\title{
Cavity prediction in sand mould production applying the DISAMATIC process
}

Hovad, Emil; Larsen, Per; Spangenberg, Jon; Walther, Jens Honore; Thorborg, Jesper; Hattel, Jesper Henri

Published in:

Powder Technology

Link to article, DOI:

10.1016/j.powtec.2017.08.037

Publication date:

2017

Document Version

Peer reviewed version

Link back to DTU Orbit

Citation $(A P A)$ :

Hovad, E., Larsen, P., Spangenberg, J., Walther, J. H., Thorborg, J., \& Hattel, J. H. (2017). Cavity prediction in sand mould production applying the DISAMATIC process. Powder Technology, 321, 204-217.

https://doi.org/10.1016/j.powtec.2017.08.037

\section{General rights}

Copyright and moral rights for the publications made accessible in the public portal are retained by the authors and/or other copyright owners and it is a condition of accessing publications that users recognise and abide by the legal requirements associated with these rights.

- Users may download and print one copy of any publication from the public portal for the purpose of private study or research.

- You may not further distribute the material or use it for any profit-making activity or commercial gain

- You may freely distribute the URL identifying the publication in the public portal 


\section{Accepted Manuscript}

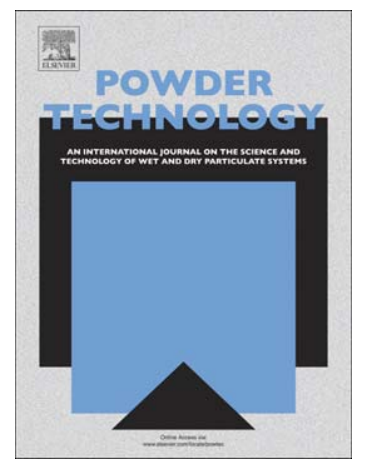

PII:

S0032-5910(17)30680-0

Reference:

doi: $10.1016 / j . p o w t e c .2017 .08 .037$

PTEC 12776

To appear in: $\quad$ Powder Technology

Received date: 27 March 2017

Revised date: $\quad 14$ July 2017

Accepted date: 9 August 2017

Please cite this article as: Emil Hovad, Per Larsen, Jon Spangenberg, Jens H. Walther, Jesper Thorborg, Jesper H. Hattel, Cavity prediction in sand mould production applying the DISAMATIC process, Powder Technology (2017), doi:10.1016/j.powtec.2017.08.037

This is a PDF file of an unedited manuscript that has been accepted for publication. As a service to our customers we are providing this early version of the manuscript. The manuscript will undergo copyediting, typesetting, and review of the resulting proof before it is published in its final form. Please note that during the production process errors may be discovered which could affect the content, and all legal disclaimers that apply to the journal pertain. 


\title{
Cavity prediction in sand mould production applying the DISAMATIC process ${ }^{2}$
}

\author{
Emil Hovad ${ }^{\mathrm{a}, \mathrm{c}}$, Per Larsen ${ }^{\mathrm{c}}$, Jon Spangenberga ${ }^{\mathrm{a}}$, Jens H. Walther ${ }^{\mathrm{a}, \mathrm{d}}$, Jesper \\ Thorborg $^{\mathrm{a}, \mathrm{b}}$, Jesper H. Hattel ${ }^{\mathrm{a}}$ \\ ${ }^{a}$ Department of Mechanical Engineering, Technical University of Denmark (DTU), \\ Denmark. Produktionstorvet, Building 425, DK-2800 Kgs., Lyngby, Denmark. \\ ${ }^{b}$ MAGMA Giessereitechnologie GmbH, Kackertstr. 11, 52072 Aachen, Germany \\ ${ }^{c}$ DISA Industries A/S, Højager 8, Høje Taastr., 2630 Taastrup, Denmark \\ ${ }^{d}$ Computational Science and Engineering Laboratory, ETH Zurich, CH 8092, Switzerland
}

\section{Abstract}

The sand shot in the DISAMATIC process is simulated by the discrete element method (DEM) taking into account the influence and coupling of the airflow with computational fluid dynamics (CFD). The DEM model is calibrated by a ring shear test, a sand pile experiment and a slump test. Subsequently, the DEM model is used to model the propagation of the green sand inside the mold chamber and the results are compared to experimental video footage. The chamber contains two cavities designed to quantify the deposited mass of green sand. The deposition of green sand in these two cavities is investigated with three cases of different air vent settings which control the ventilation of the chamber. These settings resulted in different air- and particle-velocities as well as different accumulated masses in the cavities, which were successfully simulated by the model.

Keywords: DISAMATIC process, Sand casting, Green sand, Granular flow, Discrete element method

2010 MSC: 00-01, 99-00

\footnotetext{
Fully documented templates are available in the elsarticle package on CTAN

* Corresponding author: Emil Hovad

Email address: emilh@mek.dtu.dk (Emil Hovad)
} 


\section{Introduction}

The DISAMATIC process [1] is a sand casting process applying green sand as the molding material $[2,3]$. The DISAMATIC process is typically used in the automotive industry to produce molds for metal castings in order to manufacture e.g. brake disks, differential cases and steering knuckles.

The DISAMATIC moulding process has been used since the early 1960s. Compared to conventional green sand moulding processes, it has a vertical parting line. Furthermore, it is a flaskless process, meaning there are no boxes supporting the moulds. The DISAMATIC moulding process is very productive compared to other processes, as it can produce up to 555 moulds per hour. Additionally, it can produce parts with low tolerances. Due to its efficiency and accuracy it is widespread used within the automotive sector.

The ever-rising demands to casting quality, especially within the automotive sector, lead among other things to higher demands to the mould quality. To comply with the higher demands to the mould quality, simulation tools come in handy in the development work having to be done. Until now most of the development work has been based on experience and a trial and error approach as no commercial simulation tools have been available for simulating the combined flow of green sand and air. The lack of commercial available simulation tools is partly driven by lack of material data of the green sand needed to describe the flow. Hence determination of material data has been a major part of this study.

The green sand consists mostly of quartz sand mixed with coal dust, bentonite (active clay) and water, which coats the sand grains to form a cohesive granular material where the green sand flow-ability is affected by the amount of bentonite and water. In [4] a regression model was applied to determine the relationship between the input value of the sand mixture, i.e active clay, dead clay, water content to the related output values of compactability, compressive strength, spalling strength and permeability. These relationships were developed from a DISAMATIC foundry. The green sand flow-ability was investigated in [5], [6] and the fluidized viscosity of green sand was investigated in 
[7]. In [6] it was suggested that the green sand can be investigated as an yield stress material and an analytical derivation based on the yield stress material with additional overpressure similar to the conditions when the sand enters the chamber was made in [8]. Tri-axial tests have also been performed on green sand in order to obtain the yield locus in [9]. Uni-axial compression tests were made for green sand and the stress-strain curves were analysed in [10]. Green sand was tested with a ring shear tester obtaining the yield locus and a sand pile experiment in [11].

DEM simulations of the ring shear tester have been performed in [12] where the particle shape, cohesion and static friction were investigated with respect to the resulting tangential pre-shear stress and the peak stress (yield stress). A sensitivity study was performed in [13] simulating a Schulze ring shear tester studying the effect of several material parameters on the resulting tangential pre-shear stress. The resulting tangential pre-shear stress relationship to the particle-particle static friction coefficient $\left(\mu_{s, p-p}\right)$ was asymptotic up to the value of $\mu_{s, p-p}<0.70$ and a linear dependence was found on the parameters rolling friction coefficient $\left(\mu_{r, p-p}\right)$ and the Young's modulus. A DEM adhesive elasto-plastic contact model was used to simulate uni-axial consolidation followed by unconfined compression to failure in [14].

A simulation of the sand casting process with a two phase continuum model has earlier been presented in [15] and continuum models have been designed to model granular materials as e.g. in $[16,17]$. In [18] a multiphase model was applied to simulate a core shooting process numerically in 2-D and 3-D dimensions. The DISAMATIC process was first studied with a 2-D DEM model in [19] where the granular flow was compared to video footage. This study focused on the deflection of the sand flow causing "shadow effects" around the ribs placed in the geometry of the mould. The model applied a constant particle inlet velocity and particle diameters of $2 \mathrm{~mm}$ and $4 \mathrm{~mm}$ as representative sand particle clusters for the granular flow. In [11] the same geometry was investigated with a 2-D and 3-D DEM slice model applying the representative particle cluster diameter of $2 \mathrm{~mm}$. A 2-D sensitivity study was performed with respect 
to the particle-wall interaction which showed the particle-wall values to be of less importance for the flow behaviour and filling times than e.g. particle inlet velocity. The DEM model was calibrated from experiments (ring shear test and sand pile experiment) and afterwards a velocity function for the granular flow was found from video footage.

In this study the framework of [11] is applied for calibrating the DEM model using a ring shear tester to obtain the static friction coefficients and a sand pile experiment for calibrating the rolling resistance and cohesion value for the particle-particle interaction. Additionally the mass of the DEM particle is recalculated and a slump experiment is used for calibrating the rolling resistance for the particle-wall interaction. Finally a DEM model and a CFD-DEM model are tested by simulating the flow and deposition of green sand in the two cavities and subsequently compared to the experimental observations for the three cases of the air vent settings.

\section{Governing equations}

\subsection{Granular flow: Discrete element method}

The framework of [11] is applied in this work where the commercially available software of STAR-CCM+ [20] is used for simulating the DISAMATIC process.

\subsubsection{Contact notation}

The notation for the particle contact is from [21], where particle $i$ and particle $j$ in contact are denoted by their respective positions at $\left\{\vec{r}_{i}, \vec{r}_{j}\right\}$, the velocities $\left\{\vec{v}_{i}, \vec{v}_{j}\right\}$, the angular velocities of $\left\{\vec{\omega}_{i}, \vec{\omega}_{j}\right\}$ and the distance between the two particles is denoted $r_{i j}=\left\|\vec{r}_{i}-\vec{r}_{j}\right\|_{2}$. The position vector from particle $j$ to $i$ is $\vec{r}_{i j}=\vec{r}_{i}-\vec{r}_{j}$ and the normal overlap $\delta_{i j}=\left(R_{i}+R_{j}\right)-r_{i j}=2 R$ with a uniform radius of $R$ for all the particles. 


\subsubsection{Normal contact force}

The normal force on particle $i$ from particle $j$ can be found as,

$$
\vec{F}_{n_{i j}}=\vec{n}_{i j} k_{n} \delta_{i j}^{\frac{3}{2}}-N_{n_{i j}} \vec{v}_{n_{i j}}+\vec{F}_{c o h_{i j}}
$$

$\vec{n}_{i j}=\frac{\vec{r}_{i j}}{r_{i j}}$ is the unit normal vector, $\vec{v}_{n_{i j}}$ is the relative normal velocity and $\delta_{i j}$ is the normal overlap. $N_{n_{i j}}$ is the normal non-linear damping coefficient, $F_{c o h_{i j}}$ is the cohesion, $K_{n}$ is the stiffness in the normal direction, $N_{n_{i j}}$ is the damping in the normal direction, for further details see [11]. The particle-particle constant cohesion force in the normal direction is,

$$
\vec{F}_{c o h_{i j}}=-1.5 \pi R_{\min } W \vec{n}_{i j}
$$

$R_{\text {min }}=R$ is the minimum radius of contact, $W$ is the cohesion parameter. The cohesion $\vec{F}_{\text {coh }_{i j}}$ selected is the Johnson-Kendall-Roberts (JKR) model from [22] with the factor of -1.5.

\subsubsection{Tangential contact force}

The tangential force on particle i from particle $\mathrm{j}$ can be found as,

$$
\vec{F}_{t_{i j}}=K_{t} \frac{\vec{t}_{i j}}{\left\|\vec{t}_{i j}\right\|_{2}} \delta_{t_{i j}}{ }^{\frac{3}{2}}-N_{t_{i j}} \vec{v}_{t_{i j}}+\vec{T}_{r o l_{i j}}
$$

$\vec{t}_{i j}$ is the tangential direction of the overlap, $\delta_{t_{i j}}$ is the tangential overlap, $K_{t}$ is the tangential stiffness, $G_{e q}$ is the equivalent shear modulus, $N_{t_{i j}}$ is the tangential non-linear damping coefficient. The rolling resistance for the particleparticle interaction used is the constant torque method defined as,

$$
\vec{T}_{r^{\prime} l_{i j}}=-\frac{\omega_{r e l}}{\left|\omega_{r e l}\right|} \mu_{r} R_{e q}\left|\vec{F}_{n_{i j}}\right|
$$

The relative angular velocity between the two particles is defined as $\vec{\omega}_{\text {rel }}=$ $\vec{\omega}_{i}-\vec{\omega}_{j}$ and the torque from the rolling resistance is $\vec{T}_{\text {rol }}$.

Note that there is a maximal tangential force due to Coulomb's law,

$$
\left\|\mu_{s} \vec{F}_{n_{i j}}\right\|_{2}<\left\|\vec{F}_{t_{i j}}\right\|_{2}
$$

the particle-particle static friction coefficient is denoted $\mu_{s, p-p}$ and particle-wall static friction coefficient is denoted $\mu_{s, p-w}$. 


\subsubsection{Summing the forces}

The total resultant force on particle $i$ is then computed by summing the contributions of all particles $j$ with which it currently interacts, thus:

$$
\vec{F}_{i}^{t o t}=m_{i} \vec{g}+\sum_{j}\left(\vec{F}_{n_{i j}}+\vec{F}_{t_{i j}}\right)
$$

where $\vec{g}$ is the acceleration due to gravity. The total torque acting on particle $i$ is given by

$$
\vec{T}_{i}^{t o t}=-R_{i} \sum_{j} \vec{n}_{i j} \times \vec{F}_{t_{i j}}
$$

From these two expressions the acceleration, velocity, position and rotation, are calculated by Newton's second law, numerically for each time step.

\subsection{Air flow: Navier Stokes equations}

The low air pressures $(P)$ measured in the chamber during the sand shot and the corresponding low air velocities $\left(\mathbf{v}_{g}\right)$ make the assumption of the air phase being an incompressible fluid valid for small values of the Mach number $\leq 0.3$. Then the continuity equation becomes,

$$
\rho_{g} \frac{\partial}{\partial t}\left(\epsilon_{g}\right)+\rho_{g} \nabla \cdot\left(\epsilon_{g} \mathbf{v}_{g}\right)=0
$$

where $\epsilon_{g}$ is the air volume fraction found from $\epsilon_{g}=\frac{V_{g}}{V_{g}+V_{s}}$ where $V_{g}$ is the volume of the air phase and $V_{s}$ is the volume of solid phase. Navier-Stokes equations for the incompressible air phase are,

$$
\rho_{g} \frac{\partial}{\partial t}\left(\epsilon_{g} \mathbf{v}_{g}\right)+\rho_{g} \nabla \cdot\left(\epsilon_{g} \mathbf{v}_{g} \mathbf{v}_{g}\right)=-\epsilon_{g} \nabla P+\epsilon_{g} \rho_{g} \mathbf{g}-\nabla \cdot\left(\epsilon_{g} \tau_{\mathbf{g}}\right)-\mathbf{I}_{f}
$$

where $\rho_{g}=1.18415 \frac{\mathrm{kg}}{\mathrm{m}^{3}}$ is the density of the air phase, $\mathrm{g}=[0,-9.82,0] \frac{\mathrm{m}}{\mathrm{s}^{2}}$ is gravity and the shear stress on the air is $\tau_{g}$ where the air is assumed to be a Newtonian fluid with the dynamic viscosity of $\mu=1.85508 \times 10^{-5} \mathrm{~Pa} \cdot \mathrm{s}$. The two-way coupling between the air phase and the solid phase is enforced via the inter-phase momentum transfer of $\mathbf{I}_{f}$ due to the drag on the solid phase. 


\subsection{The inter-phase momentum transfer}

A source smoothing method is applied for the inter-phase momentum transfer of $\mathbf{I}_{f}$ which averages the momentum transfer from larger parts of the mesh to the solid phase stabilizing the simulations to ensure converging simulations. The drag force on the solid phase is,

$$
\mathbf{F}_{D}=-\frac{1}{8} \pi d^{2} \rho_{g} C_{d}\left(\mathbf{v}_{g}-\mathbf{u}\right)\left|\mathbf{v}_{g}-\mathbf{u}\right|
$$

where $\mathbf{u}$ is the velocity of the solid phase and $d$ is the diameter of the particle. The interaction of the solid phase with the air phase is described by the SchillerNaumann drag model,

$$
C_{d}\left(R e_{p}\right)= \begin{cases}\frac{24}{R e_{p}}\left(1+0.15 R e_{p}^{0.687}\right), & R e_{p} \leq 10^{3} \\ 0.44, & R e_{p}>10^{3}\end{cases}
$$

where $R e_{p}$ is the particle Reynolds number and it is defined as,

$$
R e_{p}=\frac{\rho_{g}\left|\mathbf{v}_{g}-\mathbf{u}\right| d}{\mu}
$$

where $\left|\mathbf{v}_{g}-\mathbf{u}\right|$ is the slip velocity.

\subsection{Turbulence model}

Modelling the air phase as a continuum is done by solving Navier Stokes equations with the finite volume method (FVM) applying a polyhedral mesh. The $\mathrm{k}-\epsilon$ turbulence model is used and all the methods are described in [20].

\section{The green sand tests and calibrating of the DEM model}

The following green sand tests and calibrations of the DEM model are performed.

\subsection{The water content test}

The percentage of water content is found by heating a sample of green sand and measuring the mass of water which is lost. The details of the water content test also denoted the moisture determination is described in [3]. This is a standard test typically performed in a foundry. 


\subsection{The Schulze ring shear tester}

The Schulze ring shear tester is applied for characterizing the flow of granular materials in order to obtain the yield locus and the wall yield locus. The test procedures can be found in $[23,24]$. The particle-wall static friction coefficient $\left(\mu_{s, p-w}\right)$ is acquired directly from the wall friction angle as demonstrated in [11]. The particle-particle static friction coefficient in the simulation is found directly from the linearized yield locus angle. The linearized yield locus angle is described in $[11,23,24,25]$.

\subsection{The sand pile experiment and the DEM calibration.}

The sand pile experiment is applied for characterizing and calibrating the DEM model with respect to the height of the sand pile $\left(h_{p}\right)$ above the box $\mathrm{cf}$. Fig. 1(left) and described in [11]. The parameters that are calibrated from the sand pile height are the particle-particle rolling resistance interaction $\left(\mu_{r, p-p}\right)$ and the particle-particle cohesion value $\left(W_{p-p}\right)$.

\section{[Figure 1 about here.]}

\subsection{The compactability test}

The compactability test described in $[3,11]$ is applied to characterize the green sand condition and this is the standard test performed in the foundries. The green sand is poured into the cylinder with a tube filler accessory, subsequently the mass is measured before the ramming and from this the loose density of the green sand $\rho_{\text {exp }}$ is calculated cf. Fig. 1(middle). The compactability of the sand mixture is finally found by the rammer method described in [3]. The cylinder has a height of $H_{c y l}=0.12 \mathrm{~m}$ and a diameter of $D_{c y l}=0.05 \mathrm{~m}$.

\subsection{Scaling the DEM particle density}

The preliminary density of the DEM particles $\left(\rho_{D E M}{ }^{\dagger}\right)$ used in the sand pile simulations (Fig. 1(left)) is corrected to $\rho_{D E M}{ }^{*}$ to obtain a correct simulated 
bulk density $\left(\rho_{\text {sim }}{ }^{*}\right)$ equal to the loose density measured before the ramming $\left(\rho_{\text {exp }}\right)$ cf. Fig. 1(middle)

$$
\rho_{D E M^{*}} \approx \rho_{D E M}{ }^{\dagger}\left(\frac{\rho_{\exp }}{\rho_{\text {sim }}}\right) .
$$

Here $\rho_{\text {sim }}$ denotes the preliminary bulk density obtained from the sand pile simulation. Thus the subsequent slump calibration has the correct simulated bulk density $\left(\rho_{\text {sim }}{ }^{*}\right)$ shown in Fig. 1(right).

\subsection{The slump cylinder experiment and the DEM calibration}

The slump cylinder experiment is performed by lifting the cylinder rapidly upwards emulating the instantaneous wall opening in the simulation to finally find the slump length. The cylinder applied for the slump test is the same as the cylinder applied in the compactability test. The slump cylinder experiment is shown in Fig. 2(top) and the slump simulation is shown in Fig. 2(bottom).

\section{[Figure 2 about here.]}

When the green sand slump has settled the two diameters orthogonal to each other $\left(l_{x}, l_{y}\right)$ are measured and the average is calculated for the final slump length $l_{p}$ where the simulated slump length is found in a similar way from the algorithm first applied in [26] and described in [25]. The rolling resistance of the particle-wall interaction $\mu_{r, p-w}$ is calibrated with respect to the slump length. The slump simulation is applying the values found from the earlier calibrations together with the re-calculated DEM particle density $\left(\rho_{D E M}{ }^{*}\right)$.

For a correct density in the slump simulation the number of initial injected particles are found from the re-calculated DEM particle density $\left(\rho_{D E M}{ }^{*}\right)$ together with the experimental loose density in the cylinder $(\rho)$ in the following way,

$$
N \approx \frac{\rho_{\text {sim }} H_{c y l} \frac{\pi}{4} D_{c y l}^{2}}{\rho_{D E M} * \frac{\pi}{6} d^{3}}
$$

The particle are initially placed on an initial lattice with an initial random velocity to ensure a random packing. 


\section{The experimental tests of the DISAMATIC process}

\subsection{The DISAMATIC process}

The DISAMATIC process is illustrated with a special setup in the chamber shown in Fig. 3 with two cavities on the left hand side each having a narrow opening for testing the ability of green sand to enter the two cavities. During the sand shot the compressed air in the air tank drives the sand flow vertically down from the hopper through the sand slot into the chamber filling the mold chamber and the two cavities.

[Figure 3 about here.]

In the casting process the sand mold is squeezed also, but in this experiment the swing plate on the left hand side is opened instead and the green sand is then brushed out of the cavities so that the mass of the green sand in the cavities can be measured at the end of each experiment. The flow inside the chamber is captured with the video camera $\left(v_{1}\right)$ placed on the right hand side on the chamber (Pressure plate: PP) and photos are shown in Fig. 4 for eight stages of the sand shot.

[Figure 4 about here.]

The red light shown in Fig. 4(a) indicates when the valve between the air tank and the hopper is activated, this moment is defined as $t_{\text {start }}=0$. A very short time after the valve activation the air pressure over the sand in the hopper starts to increase. Later during the sand shot, the sand starts flowing into the chamber shown in Fig. 4(a) and this moment is denoted $t_{0}$. Seven lines are marked to quantify the seven filling times $t_{1}-t_{7}$, which is defined as when the green sand reaches the seven lines as shown in Fig. 4(b)-(h).

In Fig. 5 the flow in the cavities is captured with the mini video cameras $v_{2}$ and $v_{3}$ where the filling times of the cavities are monitored as $t_{1}$ when the sand enters the cavity and $t_{2}$ when the camera is blocked by the green sand. The times for the two cavities are denoted the following way: For the bottom cavity $t_{b, 1}$ and $t_{b, 2}$ and for the top cavity $t_{t, 1}$ and $t_{t, 2}$. 
[Figure 5 about here.]

\subsection{The two air vent types}

Two types of air vents are applied for ventilating the chamber where one type is placed in the chamber $\left(a_{c}\right)$ and another type is placed on the SP side inside the cavities $\left(a_{p}\right)$. Experiments for the air vents flow rate versus pressure drop are shown for the air vent in the chamber in Fig. 6(blue line) and for the air vents on the pattern plate in Fig. 6(black line). The pattern plate air vents are placed in the cavities.

[Figure 6 about here.]

The physical behaviour shown in Fig. 6 resembles the Darcy flow,

$$
Q=-a \Delta p
$$

where $Q$ is the air flow rate and $\Delta P$ is the pressure difference across the air vent and $a$ is the permeability of the air vent. The chamber air vent type has the value of $a_{c}=1.274 \times 10^{-6} \frac{\mathrm{m}^{3}}{\mathrm{sPa}}$ and the air vent type placed in the cavities on the pattern plate has the value of $a_{p}=2.34 \times 10^{-6} \frac{\mathrm{m}^{3}}{\mathrm{sPa}}$.

\subsection{The air vent settings and the three test cases}

The air vents and their positions are illustrated in Fig. 7 where a total of 294 air vents are opened and this is denoted case 1 . There are 238 air vents of the type $a_{c}$ where 112 air vents are placed at the top of the PP chamber side, 52 air vents are placed at the top of the SP side shown in Fig. 7(Chamber top view) and $2 \times 37$ air vents are placed on the chamber sides in Fig. 7(Chamber side view). On the pattern plate shown in Fig. 7(Swing plate view) each cavity has 28 cavity air vents of the type $\left(a_{p}\right)$ where the purpose of the air vents in the cavities is to ensure a better ventilation and thereby transporting a larger amount of green sand into the cavities.

[Figure 7 about here.] 
The three cases of the air vents settings are investigated with 2.0 bar overpressure where the three air vent settings are presented in table 1. The three air vents settings are: case 1 with all the air vents opened, case 2 with all the air vents closed in the top of the SP side and 5 closed side air vents and finally case 3 with 14 air vents closed in each pattern plate.

[Table 1 about here.]

The chamber measurements without the pattern plate have the width $W=$ $0.50 \mathrm{~m}$, height $H=0.48 \mathrm{~m}$ and depth $D=0.60 \mathrm{~m}$. The cavities in the pattern plate has the depth $D_{c}=0.57 \mathrm{~m}$ and is also centred at the middle of the chamber depth. The orifice opening height of the cavities are set to $0.015 \mathrm{~m}$ and the height of the cavities is $H_{c}=0.085 \mathrm{~m}$. The sand slot has the width $W_{i}=0.04 \mathrm{~m}$ and a depth $D_{s}=0.54 \mathrm{~m}$ and is centred at the middle of the chamber depth. The encapsulation areas for the air vents $A_{p}, A_{S P}, A_{P P}$ are applied for calculating the porous resistance for the simulations together with the two types of air vents in eq. 18 .

\section{Simulation settings for the DISAMATIC process}

5.1. The simulated geometry

[Figure 8 about here.]

The flow is modelled as a 3-D slice placed in the middle of the chamber shown in Fig. 8 with a slice depth of $D_{s}=0.01 \mathrm{~m}$ in the z-direction where this direction has symmetry. Thereby the side air vents are not simulated due to the slice geometry of the simulation.

\subsection{Boundary conditions for the granular flow}

\subsubsection{DEM particle flow rate}

The chamber is divided into the eight different volumes $\left(V_{1}-V_{8}\right)$ where $V_{n}=A_{n} D_{s}$ and the sand jet is included in the first volume $\left(V_{1}\right)$ and thereby excluded from the other volumes as shown in Fig. 8. The volumes are filled with 
green sand at the subsequent filling times $\left(t_{1}-t_{7}\right)$. From this the flow rates are calculated $\left(f_{1}-f_{7}\right)$ where the flow rate for the last area $A_{8}$ is assumed to be equal to the flow rate of $f_{7}$. The particle flow rate function $f_{y}(t)$ in the DEM simulations is calculated from the volumes of the chamber $V_{1}-V_{7}$ (neglecting the cavities on the swing plate) multiplied with the maximum particle packing fraction of approximately $\eta_{h}=0.74$ divided with the volume of the particle and the individual flow rate intervals $\Delta t_{1}=t_{1}, \Delta t_{2}=t_{2}-t_{1}, \Delta t_{3}=t_{3}-t_{2}$ etc. in the following way,

$$
f_{n}=\frac{V_{n} \eta_{h}}{\frac{\pi}{6} d^{3} \Delta t_{n}}
$$

Volume conservation for the number of injected particles is established in the transition zone from the flow rate of $f_{n}$ to $f_{n+1}$ with a linear interpolation in the time interval of $\Delta t_{n, s}=\min \left(\Delta t_{n}, \Delta t_{n+1}\right)$. The slope of linear interpolation in the time interval is calculated as $s_{n}=\frac{f_{n+1}-f_{n}}{\Delta t_{n, s}}$ and the particle flow rate function $f_{y}(t)$ then becomes,

$$
\begin{array}{ll}
f_{y}(t)=f_{n} & \text { if } t_{n-1}+\frac{\Delta t_{n-1, s}}{2} \leq t \leq t_{n}-\frac{\Delta t_{n, s}}{2} \\
f_{y}(t)=f_{n}+\left(t-\left(t_{n}-\frac{\Delta t_{n, s}}{2}\right)\right) s_{n} & \text { if } \quad t_{n}-\frac{\Delta t_{n, s}}{2} \leq t \leq t_{n}+\frac{\Delta t_{n, s}}{2}
\end{array}
$$

The calculated flow rate of $f_{y}(t)$ is applied for all the following DEM particle inlet velocities. The filling times applied for obtaining the flow rate are shown in Fig. 9 where the full lines represent the selected experiment used for simulating each of the three cases.

\subsubsection{DEM particle inlet velocity}

The time dependent inlet particle velocity $\left(v_{y}(t)\right)$ in the vertical $y$-direction is obtained from the estimated velocities $v_{n}=\frac{A_{n}}{t_{n} W_{i}}$, where the seven areas $\left(A_{1}-\right.$ $A_{7}$ ) are shown in Fig. 8. The transition from velocity $v_{n}$ to $v_{n+1}$ is found using eq. 17.

[Figure 9 about here.]

The filling times $\left(t_{1}-t_{7}\right)$ used for calculating the inlet velocity are shown in Fig. 9 for the selected experiments. The resulting time dependent velocities 
$v_{y}(t)$ for three simulations are shown in Fig. 10(a) where the spikes are due to the video frame rate 60 frames/s making it difficult to exactly determine the filling times shown in Fig. 9. To smooth out the spikes a two stage time dependent inlet velocity $v_{2 y}(t)$ is constructed, where $v_{1}$ and $v_{2}$ are connected by eq. 17. The first constant velocity is obtained as previously whereas the second constant velocity $v_{2}$ is chosen among the velocities $v_{y}\left(t>t_{1}\right)$ with the longest duration cf. Fig. 10(a). An exception is made in case 3, where the second longest time duration is chosen to avoid an otherwise unrealistic velocity. The two stage time dependent inlet velocities are shown in Fig. 10(b). Lastly, two constant particle velocities of $v_{y}(t)=-5 \frac{\mathrm{m}}{\mathrm{s}}$ and of $v_{y}(t)=-7 \frac{\mathrm{m}}{\mathrm{s}}$ are considered. For each of the three cases all the four different vertical velocities are simulated for both pure DEM simulations (vacuum) and CFD-DEM (including air phase) and this gives a total of 24 simulations.

\section{[Figure 10 about here.]}

A normal distribution is applied for the horizontal velocity to emulate the random nature of the green sand flow in the chamber and was originally applied in [11]. Thus, the horizontal velocity $v_{x}(t)$ has a mean of $0.0 \frac{\mathrm{m}}{\mathrm{s}}$ and a standard deviation $0.1 \frac{\mathrm{m}}{\mathrm{s}}$ and a maximum fluctuation of $\pm 1.0 \frac{\mathrm{m}}{\mathrm{s}}$ as in [11].

\subsection{Boundary conditions for the air flow}

\subsubsection{Air inlet pressure}

In this study the focus is on simulating the flow of air and green sand in the chamber, the air inlet pressure boundary for the chamber is placed at the sand slot where the green sand also enters, as shown in Fig. 11. The air pressure at the boundary is obtained from the top pressure sensor shown in Fig. 7(red circle).

\subsubsection{Air outlets}

A symmetry boundary is applied in the $z$-direction (depth direction) which resembles the conditions in the center of the mold during the sand shot and the 
boundary is shown in Fig. 11. The mesh has a polyhedral structure with the cell size of $\Delta x=0.025 \mathrm{~m}$ giving the number of cells of around $\approx 9000$. There are 4 porous baffle interfaces in the chamber each having an elongated air channel with a pressure outlet set to 0 bar relative to the pressure of the inlet.

[Figure 11 about here.]

\subsubsection{Air outlet: Darcy flow in the porous baffle}

The DISAMATIC air vents from eq. 15 are set in parallel because the $n$ air vents are positioned side by side in the areas $(A)$,

$$
\beta=\frac{A}{\rho_{g} a n}
$$

$\beta$ is the constant porous viscous resistance [20] and is determined by the air vent type $(a)$, the number of air vents $(n)$ over the cross sectional area $(A)$ and the density of the fluid $\rho_{g}$. The placements and areas of the air vents are illustrated in Fig. 7 and for the simulation shown in Fig. 11. The outlet boundary settings for all the three cases are shown in table 2 where in case 2 and in case 3 a number of air vents are blocked and thereby the porous areas are changed together with $\beta$.

[Table 2 about here.]

\subsection{Monitoring the simulated flow}

The seven filling times $t_{1}-t_{7}$ are monitored for the simulations and found from the particle filling of the seven volumes $\left(V_{1}-V_{7}\right)$. A volume $V_{n}$ is filled when the minimum volume of particles $V_{p}$ is above the packing fraction of 0.4 and thereby the filling time is monitored $t_{n}$.

The mass of the DEM particles in the cavities of the slice geometry $D_{s}$ are monitored with respect to time and scaled with $\frac{D_{c}}{D_{s}}=57$ due to the ratio of the simulated geometry depth $D_{s}$ versus the experimental depth of the cavities $D_{c}$. 


\section{Results of the green sand tests and the calibrations}

\subsection{Results of the green sand tests}

The result of particle-particle static friction coefficient and the particle-wall static friction coefficient from the ring shear test, the sand pile height, the green sand density, the slump length, the compactability and water content are shown in table 3 .

[Table 3 about here.]

\subsection{Calibration of the DEM model}

\subsubsection{General settings for all the DEM simulations}

The radius of the DEM particle, coefficient of restitution, Poisson's ratio and Young's modulus are obtained the framework of [11] and listed in table 4. The particle-wall static friction coefficient applied in the simulation takes the value of $\mu_{s, p-w}=0.33$ corresponding to the average value obtained from the ring shear tests for the green sand samples interaction with a stainless steel plate with the procedure described in [11]. The particle-particle static friction coefficient of $\mu_{s, p-p}=0.57$ is obtained from the ring shear test's linearized yield locus angle, where all the parameters are listed in table 3.

[Table 4 about here.]

In the sand pile simulations it is assumed that the particle-wall rolling resistance is $\mu_{r, p-w}=0.4$, this is a reasonable assumption based on prior simulations of the slump cylinder test. Note, that the particle-wall rolling resistance $\mu_{r, p-w}$ will be calibrated later in the slump cylinder simulation. The initial DEM particle density of $\rho_{D E M^{\dagger}}=1750 \frac{\mathrm{kg}}{\mathrm{m}^{3}}$ is a reasonable assumption based on prior simulations of the sand pile density.

\subsubsection{Results of the sand pile calibration}

The experimental sand pile height is plotted together with the simulated sand pile heights in Fig. 12. The simulations with $\mu_{r, p-p}=0.4$ and $W_{p-p}=$ 
$0.3 \frac{\mathrm{J}}{\mathrm{m}^{2}}$ (blue dotted line) and $\mu_{r, p-p}=0.2$ and $W_{p-p}=0.5 \frac{\mathrm{J}}{\mathrm{m}^{2}}$ (red dot) both give values of the height which are within the standard deviation of the measured height shown in Fig. 12. The selected parameters are $\mu_{r, p-p}=0.4$ and $W_{p-p}=$ $0.3 \frac{\mathrm{J}}{\mathrm{m}^{2}}$ because they give a more conically shaped sand pile which was also observed in the experiments and described in [11].

[Figure 12 about here.]

\subsubsection{Re-calculating the DEM particle density}

In Fig. 13 the simulated sand pile density $\left(\rho_{\text {sim }}\right)$ is compared to the experimental loose poured bulk density $\left(\rho_{\text {exp }}\right)$ measured in the cylinder before the compactability test.

[Figure 13 about here.]

The chosen particle density for the sand pile simulation is $\rho_{D E M^{\dagger}}=1750 \frac{\mathrm{kg}}{\mathrm{m}^{3}}$ which is too small for the selected $h_{p}$ with the particle-particle value of $\mu_{r, p-p}=$ 0.4 and $W_{p-p}=0.3 \frac{\mathrm{J}}{\mathrm{m}^{2}}$ when compared to the bulk density measured in the cylinder. Therefore the density is re-calculated from eq. 13 which gives $\rho_{D E M}{ }^{*}=$ $1900 \frac{\mathrm{kg}}{\mathrm{m}^{3}}$.

\subsubsection{Results of the slump length simulation}

The slump simulation is applied for determining the particle-wall rolling resistance $\mu_{r, p-w}$ with less than a standard deviation away from the the slump experiment $l_{p}$. The obtained values from the sand pile experiment of $\mu_{r, p-p}=$ 0.4 and $W_{p-p}=0.3 \frac{\mathrm{J}}{\mathrm{m}^{3}}$, the scaled DEM particle density of $\rho_{D E M}{ }^{*}=1900 \frac{\mathrm{kg}}{\mathrm{m}^{3}}$ and the number of particles injected into the cylinder which is found from eq. 3.6 are applied for the slump calibration.

[Figure 14 about here.]

The slump length result from the experiment is shown in Fig. 14 where the mean slump length $l_{p}$ is the black diamond and the standard deviation is indicated by the two black horizontal lines. The particle-wall interaction of $\mu_{r, p-w}=0.5$ is 
below a standard deviation away from the average experimental slump length shown in Fig. 14.

\subsubsection{Settings for the final simulations of the DISAMATIC process}

The results from the calibration of the DEM model are listed in table 5 where the general simulation settings were presented in table 4 .

[Table 5 about here.]

\section{Results of the DISAMATIC process and simulations}

\subsection{Experimental air pressures measured from the sensors}

For the selected sand shot in case 1, the measured air pressures can be seen as a function of time in Fig. 15. The air pressure builds up in the hopper (black line) in the start of the sand shot as the pressure decreases in the air tank (black dotted line) shown in Fig. 15. The pressure in the hopper starts to decrease after $t_{1}$ when the green sand has reached the bottom line $l_{1}$ of the chamber shown earlier in Fig. 4(b). The pressure decrease in the hopper is due to a equilibrium pressure is reached with the air tank and the air pressure now drops and the air flow propagates towards the chamber. In Fig. 15 the duration of time from $t_{0}$ to $t_{1}$ is longer than the subsequent next time intervals $t_{1}$ to $t_{2}$ etc. which is due to the larger pressure difference in the hopper versus the chamber. Video footage of the times $t_{0}-t_{7}$ are shown in Fig. 4(a)-(h) for the selected sand shot in case 1. The filling times of the two cavities with the top cavity times $t_{t, 1}-t_{t, 2}$ (red) and the bottom cavity times $t_{b, 1}-t_{b, 2}$ (blue) are shown in Fig. 15.

[Figure 15 about here.]

The green sand starts entering the chamber at the monitored time of $t_{0}$ at this time the air pressure in the top of the chamber starts slowly to increase which is shown in Fig. 16 for the three selected cases. The air pressure in the top of the chamber shown in Fig. 16 is plotted from the time of $t_{0}$ where the green sand starts to enter the chamber, which is chosen to be the initial starting time for 
the simulations. The three plotted pressures are applied as the sand slot inlet pressure in the CFD-DEM simulations with the minimum pressure of zero.

[Figure 16 about here.]

\subsection{The filling times $t_{0}-t_{7}$ of the chamber}

The selected experimental and simulation filling times for case 1 are shown in Fig. 17 for the initial starting time of $t_{0}=0$.

[Figure 17 about here.]

The constant velocity of $7 \frac{\mathrm{m}}{\mathrm{s}}$ and $5 \frac{\mathrm{m}}{\mathrm{s}}$ have the shortest filling times in the initial part of the simulated sand shot $t_{1}-t_{4}$ whereas the later filling times are too long $t_{4}-t_{7}$. The filling times of the time dependent velocity $v_{y}(t)$ has the best agreement with the experiments and the two stage time dependent velocity function $v_{2 y}(t)$ has the second best agreement with the experiment. The starting velocity of $v_{1}$ for both of the time dependent velocities were set too slow because the simulated filling time of $t_{1}$ was too long when compared to the experimental time shown in Fig. 17.

The filling times of the simulations and the selected experiment in case 1 are in good agreement with the other selected cases case 2 and case 3.

7.3. The sand deposited in the two cavities

[Table 6 about here.]

The deposited masses in the two cavities from the three cases and the selected experiments are listed in table 6. Considering all the experimental cases, case 2 showed the largest mass of deposited sand in both the top cavity and bottom cavity, being $1220 \mathrm{~g}$ and $933 \mathrm{~g}$, respectively. As earlier mentioned one experiment was selected for simulation for each of the three cases considered.

The simulated masses in the two cavities are monitored with respect to time and compared to the selected experiment for the three cases shown in Fig. 18 - Fig. 20. For all the three cases of the CFD-DEM simulations the deposited 
mass in the two cavities were overestimated when compared to the selected experiments. For case 3 the CFD-DEM simulations had better agreement with the selected experiment shown in Fig. 20 as compared to the other simulated cases.

[Figure 18 about here.]

[Figure 19 about here.] 
For case 1 and case 2 the deposited mass in DEM simulations' for the two cavities are underestimated when compared to the selected experiments shown in Fig. 18 - Fig. 19, except for $v_{y}(t)$ in the top cavity shown in Fig. 19(b) plotted with the blue dotted line. In case 3 the DEM simulations has a good agreement with the selected experiment shown in Fig. 20, except for $v_{y}(t)$ in especially the top cavity which is shown in Fig. 20(b) which is due to the high particle velocity in the end of the simulation shown earlier in Fig. 10(a).

The inlet velocity for the DEM particles in the simulated sand shot was initially larger for the two constant inlet particle velocities as compared to the simulations with the time dependent velocities and thereby the particles entered earlier in the bottom cavity in all the three simulated cases with DEM.

[Figure 20 about here.]

\subsection{The qualitative flow behaviour}

The CFD-DEM simulated results of case $1-3$ are shown in Fig. 21. The three simulations overestimated the mass in the cavities as when compared to the experiments and the DEM simulations. For the cases 1 and 2 simulated air velocities in the cavities were around $15-30 \frac{\mathrm{m}}{\mathrm{s}}$ as compared to case 3 where the cavity air velocities were around $10-20 \frac{\mathrm{m}}{\mathrm{s}}$. When comparing case 2 to both case 1 and case 3 in Fig. 21(middle figures) the particles have greater velocities and a more pronounced particle jet when the particles entered the bottom cavity. When comparing the simulations to the experiments shown in Fig. 21 all the simulations were in good agreement with the experiments with respect to the sand pile shape at the time $\mathrm{t}=0.50 \mathrm{~s}$.

[Figure 21 about here.] 


\section{Conclusion}

In the present paper the sand shot in the DISAMATIC process was investigated with three different air vent settings with respect to the mass of green sand deposited in two cavities, this investigation was performed experimentally as well as simulated. For the three cases all the simulations were performed with only the discrete element method (DEM) and additionally with the discrete element method (DEM) combined with computational fluid dynamics (CFD) denoted CFD-DEM. The CFD part took into account the influence and coupling of the airflow.

From the experiments the following conclusions can be drawn: With the standard air vent settings (case 1) where all the air vents were open, the experiments showed the second largest average mass in the top cavity as expected and the smallest average mass in the bottom cavity, although the average mass in the bottom cavity was only $5.1 \%$ smaller as compared to the case with half of the air vents closed in the cavities (case 3). When 52 out of 164 of the air vents were blocked in the chamber (case 2) it gave an enhanced local air flow through the cavities and as expected the mass in the two cavities were largest with at least $21.2 \%$ difference from the other cases. With half of the air vents blocked in the cavities (case 3), the smallest average mass in the top cavity was observed and the second smallest average mass in the bottom cavity was observed. Thus, the local air flow can be controlled e.g. by blocking air vents in the chamber and therefore increasing the local air flow through the air vents placed in the cavities as done in case 2. Decreasing the number of air vents in the cavities as done in case 3 decreased the deposited mass of green sand in the cavities as compared to case 2 .

From the simulations the following conclusions can be drawn: With the chosen particle flow rates and particle velocities it was possible to simulate the deposited mass of green sand in the cavities and the qualitative flow behaviour. Larger inlet velocities for the DEM particles increased the final mass in the cavities. 
The CFD-DEM simulations show larger masses in the cavities than the experimental results due to the air flow in the simulations still drags the particles into the cavities at the end of the sand shot. The side air vents could not be simulated due to the running time of the number of DEM particles when simulating a larger part of the chamber and thereby the volume of air that exits the cavities is correspondingly overestimated. In case 3 the CFD-DEM simulations were in better agreement with the selected experiment due to the lower air inlet pressure in the simulations which gave subsequently lower air velocities through the cavities.

Predictions of the mass of the green sand in the cavities were obtained with good agreement by the DEM simulations however with a tendency to underestimate the mass.

The CFD-DEM simulations predict the cavity fillings times better as compared to the DEM simulations although the CFD-DEM simulations still show too long filling times for the cavities as compared to the experiments. The results indicate that it is important to include the influence of the air flow in pneumatic transport of granular material including the 2-way coupling between the phases. 


\section{References}

[1] DISA Industries A/S, DISA 231/DISA 231 Var. Sand Moulding System Instructions for Use (9157).

[2] J. Campbell, Castings (Second Edition), Butterworth-Heinemann, 2003. doi : 10.1016/B978-075064790-8/50022-X.

URL

http://www.sciencedirect.com/science/article/pii/ B978075064790850022X

[3] Mold \& Core Test Handbook, 4rd Edition, American Foundry Society, 2015.

[4] R. Banchhor, S. Ganguly, Modeling of moulding sand characteristics in disamatic moulding line green sand casting process, Proceedings of BITCON-2015 Innovations For National Development. National Conference on: Innovations In Mechanical Engineering For Sustainable Development.

[5] Y. Chang, H. Hocheng, The flowability of bentonite bonded green molding sand, Journal of Materials Processing Technology 113 (1-3) (2001) 238-244. doi:10.1016/S0924-0136(01)00639-2.

[6] J. Bast, A new method for the measurement of flowability of green moulding sand, Archives of Metallurgy and Materials 58 (3) (2013) 945-952. doi : 10.2478/amm-2013-0107.

[7] J. Masoud, J. Spangenberg, E. Hovad, R. C. J. H. Hattel, K. I. Hartmann, D. Schuutz, Rheological characterization of green sand flow, Proceedings of the ASME 2016 International Mechanical Engineering Congress and Exposition.

[8] E. Hovad, J. Spangenberg, P. Larsen, J. Thorborg, J. H. Hattel, An analytical solution describing the shape of a yield stress material subjected to an overpressure, AIP Conference Proceedings 1738 (1). doi:http: 
//dx.doi.org/10.1063/1.4951805.

URL http://scitation.aip.org/content/aip/proceeding/aipcp/10 . $1063 / 1.4951805$

[9] J. Frost, J. Hiller, The mechanics of green sand moulding, AFS Trans 74 (1966) 177-186.

[10] F. W. S. Scott M. Strobl, Using stress-strain curves to evaluate control clay bonded moldings sands.

URL http://www.simpsongroup.com/tech/StressStrainCurves.pdf

[11] E. Hovad, J. Spangenberg, P. Larsen, J. Walther, J. Thorborg, J. Hattel, Simulating the disamatic process using the discrete element method a dynamical study of granular flow, Powder Technology 303 (2016) 228 240. doi:http://dx.doi.org/10.1016/j.powtec.2016.09.039.

URL

http://www.sciencedirect.com/science/article/pii/ S0032591016306234

[12] O. Baran, A. DeGennaro, E. Rame, A. Wilkinson, Dem simulation of a schulze ring shear tester, AIP Conference Proceedings 1145 (2009) 409412.

[13] T. A. H. Simons, R. Weiler, S. Strege, S. Bensmann, M. Schilling, A. Kwade, A ring shear tester as calibration experiment for dem simulations in agitated mixers: a sensitivity study, Procedia Engineering 102 (2015) 741-748.

[14] S. C. Thakur, J. P. Morrissey, J. Sun, J. F. Chen, J. Y. Ooi, Micromechanical analysis of cohesive granular materials using the discrete element method with an adhesive elasto-plastic contact model, Granular Matter 16 (3) (2014) 383-400. doi:10.1007/s10035-014-0506-4.

[15] J. Wu, H. Li, W. Li, H. Makino, M. Hirata, Two phase flow analysis of aeration sand filling for green sand molding machine, International Foundry Research/Giessereiforschung 60 (1) (2008) 20-28. 
[16] D. G. Schaeffer, Instability in the evolution equations describing incompressible granular flow, Journal of Differential Equations 66 (1) (1987) 19-50. doi:10.1016/0022-0396(87)90038-6.

URL

http://linkinghub.elsevier.com/retrieve/pii/ 0022039687900386

[17] P. C. Johnson, R. Jackson, Frictional-collisional constitutive relations for granular materials, with application to plane shearing, Journal of Fluid Mechanics 176 (1987) 67-93. doi:10.1017/S0022112087000570.

[18] B. Winartomo, U. Vroomen, A. Buhrig-Polacek, M. Pelzer, Multiphase modelling of core shooting process, International Journal of Cast Metals Research 18 (1) (2005) 13-20. doi:10.1179/136404605225022811.

[19] E. Hovad, P. Larsen, J. H. Walther, J. Thorborg, J. H. Hattel, Flow dynamics of green sand in the disamatic moulding process using discrete element method (dem), IOP Conference Series: Materials Science and Engineering 84 (1) (2015) 012023.

[20] STAR-CCM+, USER GUIDE STAR-CCM+, Version 8.02, 2013.

[21] L. Silbert, D. Ertas, G. Grest, T. Halsey, D. Levine, S. Plimpton, Granular flow down an inclined plane: Bagnold scaling and rheology, Physical Review E 64 (5) (2001) 051302, 051302/1-051302/14. doi : 10.1103/PhysRevE. 64. 051302 .

[22] K. L. Johnson, Contact Mechanics, 1985. doi:10.1115/1.3261297.

URL http://www.amazon.fr/Contact-Mechanics-K-L-Johnson/dp/ 0521347963

[23] D. Schulze, J. Schwedes, J. W. Carson, Powders and bulk solids: Behavior, characterization, storage and flow, Springer Berlin Heidelberg, 2008. doi: 10.1007/978-3-540-73768-1.

[24] D. Schulze, Flow properties of powders and bulk solids (2006) 1-21.

URL http://dietmar-schulze.de/grdle1.pdf 
[25] E. Hovad, Numerical simulation of flow and compression of green sand, PHD-Thesis from Danish Technical University of Denmark (DTU).

[26] J. Spangenberg, R. Cepuritis, E. Hovad, G. W. Scherer, S. Jacobsen, Shape effect of crushed sand filler on rheology: A preliminary experimental and numerical study, Rilem State of the Art Reports (2016) 193-202. 


\section{List of Figures}

1 The sand pile simulation (left), the slump experiment (middle) and the slump simulation (right) are used to calibrating the particle static friction coefficient $\left(\mu_{r, p-p}\right)$, the particle-particle cohesion value $\left(W_{p-p}\right)$ and the DEM paticle density $\left(\rho_{D E M^{*}}\right)$. The simulated bulk density inside the box is denoted $\rho_{\text {sim }}$, the loose experimental density inside the cylinder is $\rho_{\text {exp }}$ and the DEM particle density in the slump simulation is $\rho_{D E M}{ }^{*}$. The edited figure to the left are originally from $[11] \ldots \ldots \ldots . . . .$.

2 The slump cylinder test: experiment (top) and simulation (bottom). The slump filling (left), wall removal (middle) and the measurements of the slump length $l_{p}=\frac{1}{2}\left(l_{x}+l_{y}\right) . \ldots \ldots \ldots$

3 The sand shot: (a) The hopper is filled with green sand. (b) The sand shot fills the mold chamber and cavities with green sand. (c) The swing plate (SP) opens to access the green sand in the two cavities. The air pressures are monitored by sensors in the air tank (light black cross), the shot valve (green cross), the hopper (black cross), the top of the chamber (red cross) and the bottom of the chamber (blue cross). . . . . . . . . . . . .

4 (a) Video footage of the green sand starting to enter the chamber where this occurrence is defined by the time $t_{0}$. In the chamber seven equally spaced lines are drawn and indicated by the names $l_{1}-l_{7}$. (b)-(h) When the sand passes the seven lines, the seven filling times are recorded $t_{1}-t_{7} \ldots \ldots \ldots$

5 Video footage of the green sand filling of the cavity where a camera is placed in each cavity. (a) The red light indicates when the activation of the sand shot valve occurs. (b) The green sand entering the cavity $t_{1}$. (c) The filling of cavity by the green sand blocking the camera view $t_{2} \ldots \ldots \ldots \ldots$

6 The air flow rate $(Q)$ through the air vent as a function of the pressure drop $(\Delta P)$. The chamber air vent permeability is denoted $a_{c}$ (blue line) and the pattern plate air vents permeability is denoted $a_{p}$ (black line) . . . . . . . . . . . . .

7 (a) The chamber top view showing the two air outlets - one on the SP side and one on the PP side. (b) The chamber side view with the placements of pressure sensors (top and bottom), side air vents, sand slot, SP side, PP side. (c) The chamber SP view with the pattern plate area for the two air vent areas indicated by name air outlet. . . . . . . . . . . . . . . . . .

8 The flow rate found from the chamber measurements and the video footage in the chamber. The chamber is divided into the different areas $\left(A_{1}-A_{7}\right)$ that are filled with green sand at the subsequent times $\left(t_{1}-t_{7}\right) \ldots \ldots \ldots$ 
9 The average experimental filling times of $t_{0}-t_{7}$ for the three cases 1 - 3(dotted lines) and the three selected experimental filling times from cases $1-3$ (full lines). . . . . . . . . . .

10 The vertical inlet velocities for the simulations. The time dependent velocities $v_{y}(t)$ for the three cases. The two stage time dependent velocities $v_{2 y}(t)$ and the constant velocities for the three cases. . . . . . . . . . . . . . . . . . . . . 39

11 Placements of the boundaries. . . . . . . . . . . . . 40

12 The black diamond is the mean height of the green sand pile experiment of $0.054 \mathrm{~m} \pm 0.002 \mathrm{~m}$ (black horizontal lines). . . . . 41

13 Plot of the density: The black diamond is the mean density of the green sand pile experiment of $902 \pm 30 \frac{\mathrm{kg}}{\mathrm{m}^{3}}$ (thin black line). The DEM simulations were made for the settings for the cohesion value $W_{p-p}=0.3 \frac{\mathrm{J}}{\mathrm{m}^{2}}$ (blue dotted line). . . . . . . . .

14 The black diamond is the mean length (diameter) of the green sand slump experiment of $0.186 \pm 0.0548 \mathrm{~m}$ with the standard deviation of $\sigma=5.48 \mathrm{~mm}$ (thin black line). . . . . . . . . . .

Example from Case 1: The pressure as a function of time is shown in the positions listed from the top to the bottom: The air tank (black dotted line), the shot valve (green), the hopper (black line), the top of the chamber (red line) and the bottom of the chamber (blue line). The atmospheric pressure is used as the reference pressure. The filling times $t_{0}-t_{7}$ in the chamber from the chamber camera $v_{1}$ (black dotted lines). . . . . . . . . .

16 The three cases of experimental pressures measured at the top of the chamber as a function of time with the initial starting time of $t_{0}=0.0 \mathrm{~s}$. The atmospheric pressure is used as the reference pressure....................... 45

17 The experimental and simulation filling times of $t_{0}-t_{7}$ for case 1.46

18 Case 1: The mass as a function of time for the bottom cavity (a) and for the top cavity (b). . . . . . . . . . . . . 47

19 Case 2: The mass as a function of time for the bottom cavity (a) and for the top cavity (b). . . . . . . . . . . . . . . 48

20 Case 3: The mass as a function of time for the bottom cavity (a) and for the top cavity (b). . . . . . . . . . . . . . . . . 49

21 For the selected three cases: The time dependent velocity $v_{y}(t)$ simulation at time $t=0.50 \mathrm{~s}$. (Top) The velocity of the air phase. (Middle) The velocity of the particles. (Bottom) The experimen-

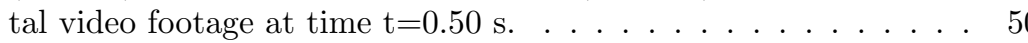




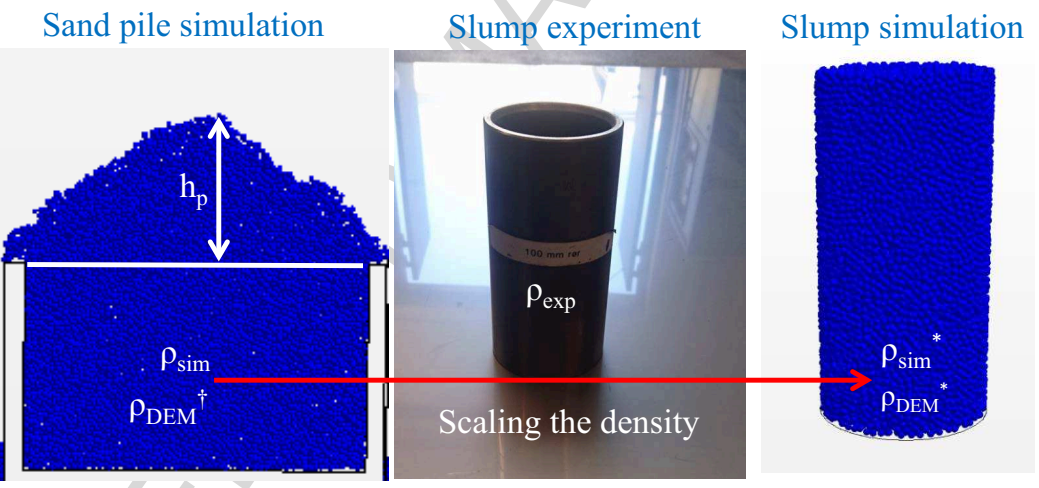

Figure 1: The sand pile simulation (left), the slump experiment (middle) and the slump simulation (right) are used to calibrating the particle static friction coefficient $\left(\mu_{r, p-p}\right)$, the particle-particle cohesion value $\left(W_{p-p}\right)$ and the DEM paticle density $\left(\rho_{D E M}{ }^{*}\right)$. The simulated bulk density inside the box is denoted $\rho_{\text {sim }}$, the loose experimental density inside the cylinder is $\rho_{\exp }$ and the DEM particle density in the slump simulation is $\rho_{D E M^{*}}$. The edited figure to the left are originally from [11]. 


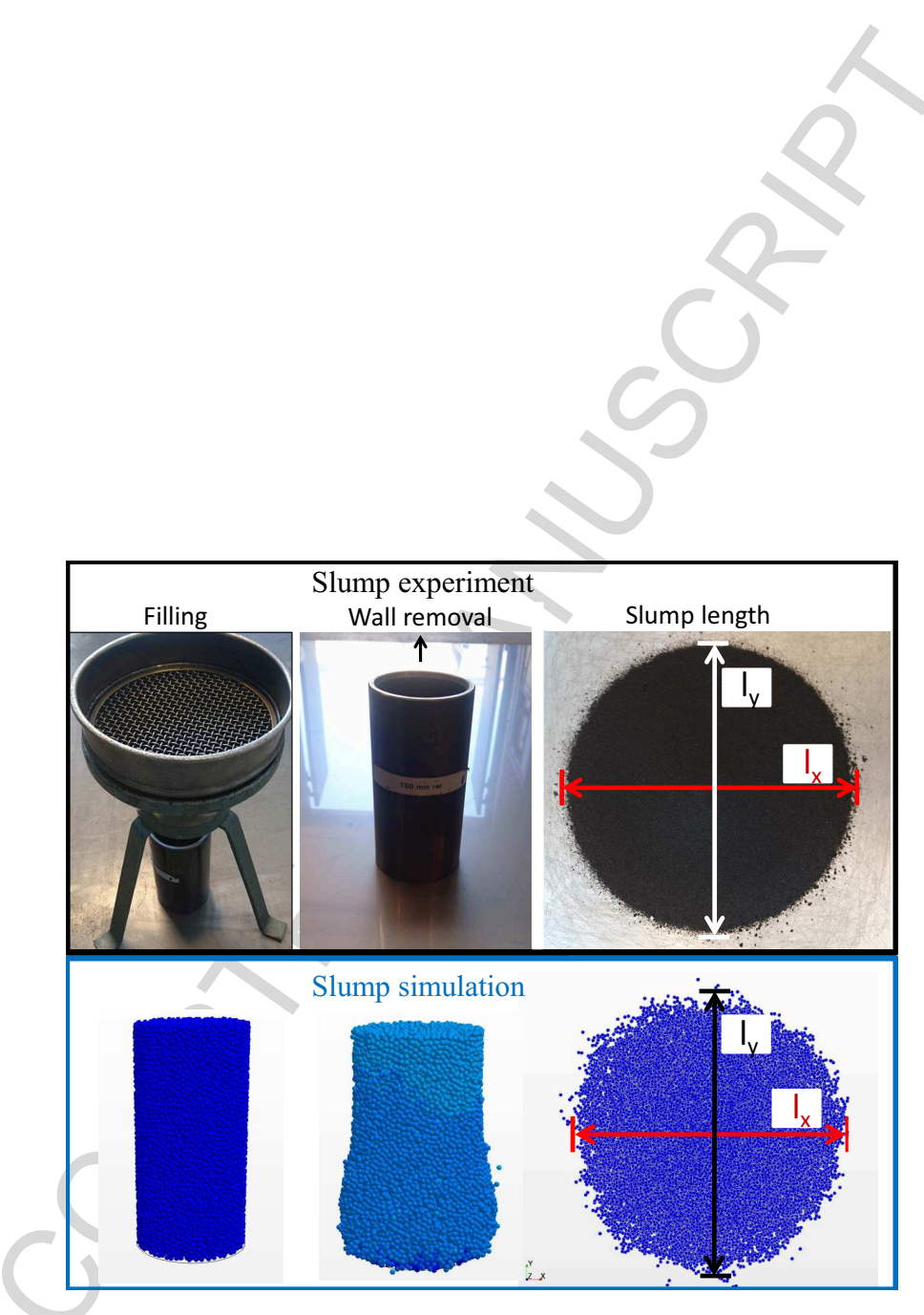

Figure 2: The slump cylinder test: experiment (top) and simulation (bottom). The slump filling (left), wall removal (middle) and the measurements of the slump length $l_{p}=\frac{1}{2}\left(l_{x}+l_{y}\right)$. 

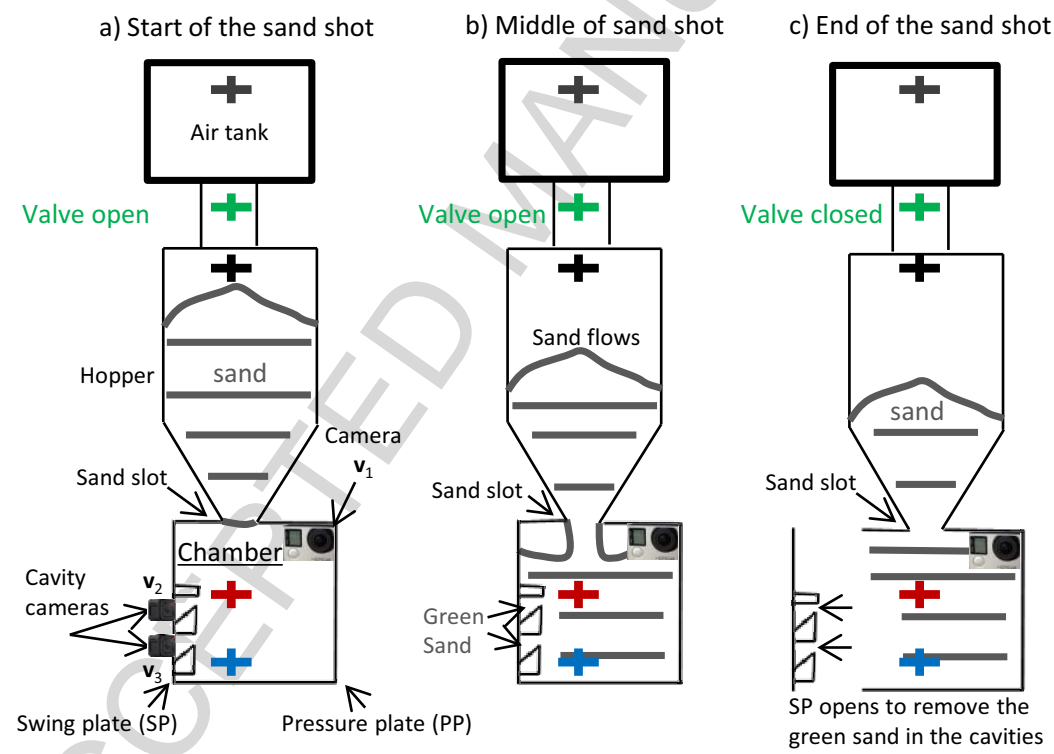

Figure 3: The sand shot: (a) The hopper is filled with green sand. (b) The sand shot fills the mold chamber and cavities with green sand. (c) The swing plate (SP) opens to access the green sand in the two cavities. The air pressures are monitored by sensors in the air tank (light black cross), the shot valve (green cross), the hopper (black cross), the top of the chamber (red cross) and the bottom of the chamber (blue cross). 


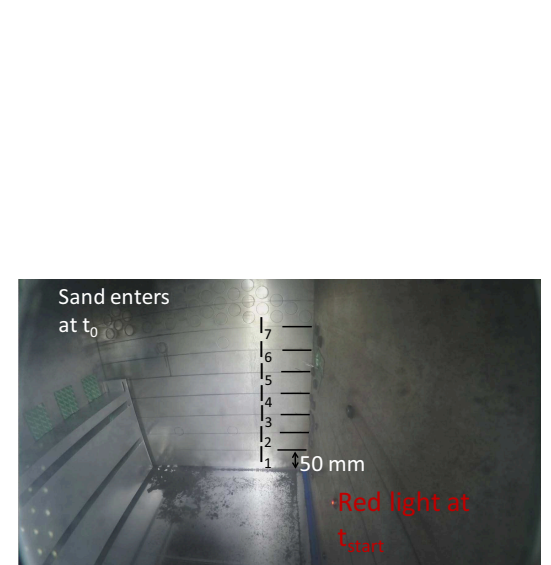

(a) Sand enters the chamber at $t_{0}$

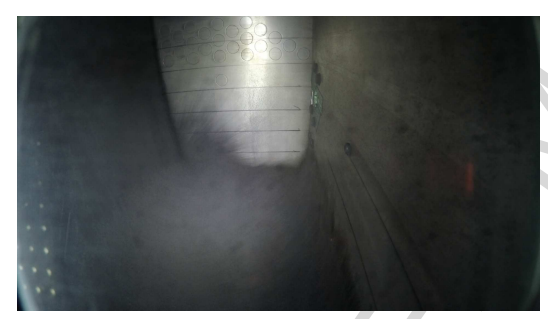

(c) $t_{2}$

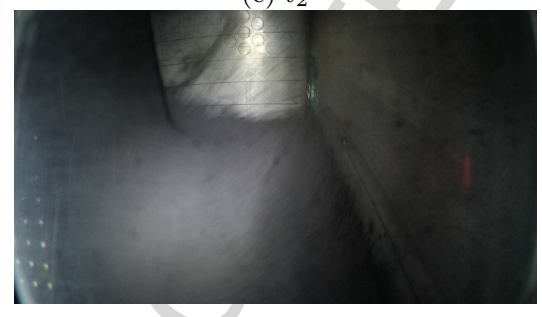

(e) $t_{4}$

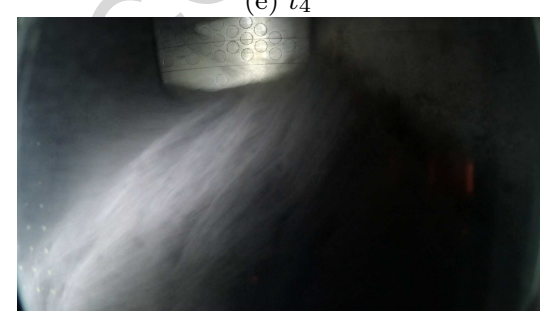

(g) $t_{6}$

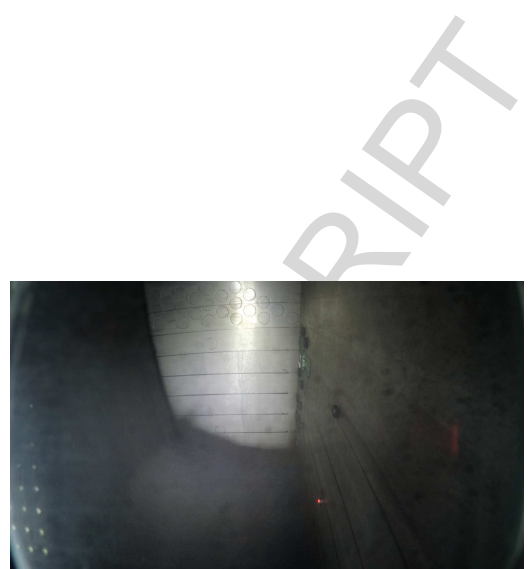

(b) $t_{1}$

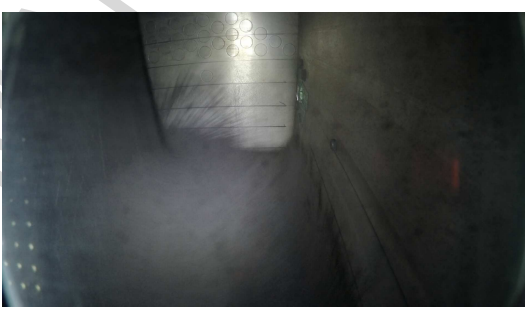

(d) $t_{3}$

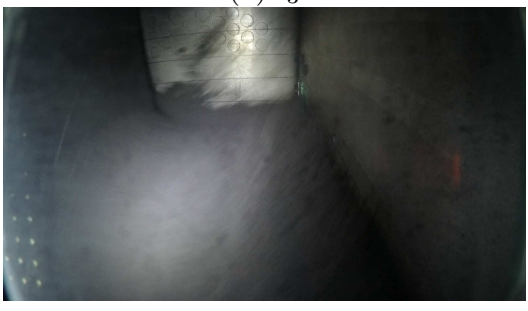

(f) $t_{5}$

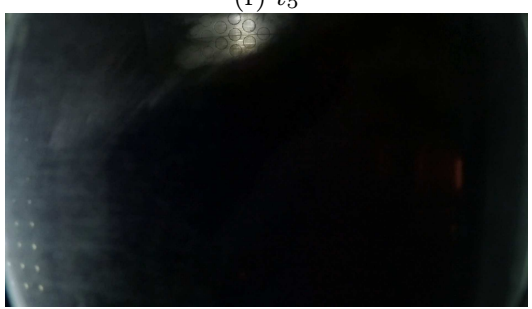

(h) $t_{7}$

Figure 4: (a) Video footage of the green sand starting to enter the chamber where this occurrence is defined by the time $t_{0}$. In the chamber seven equally spaced lines are drawn and indicated by the names $l_{1}-l_{7}$. (b)-(h) When the sand passes the seven lines, the seven filling times are recorded $t_{1}-t_{7}$. 


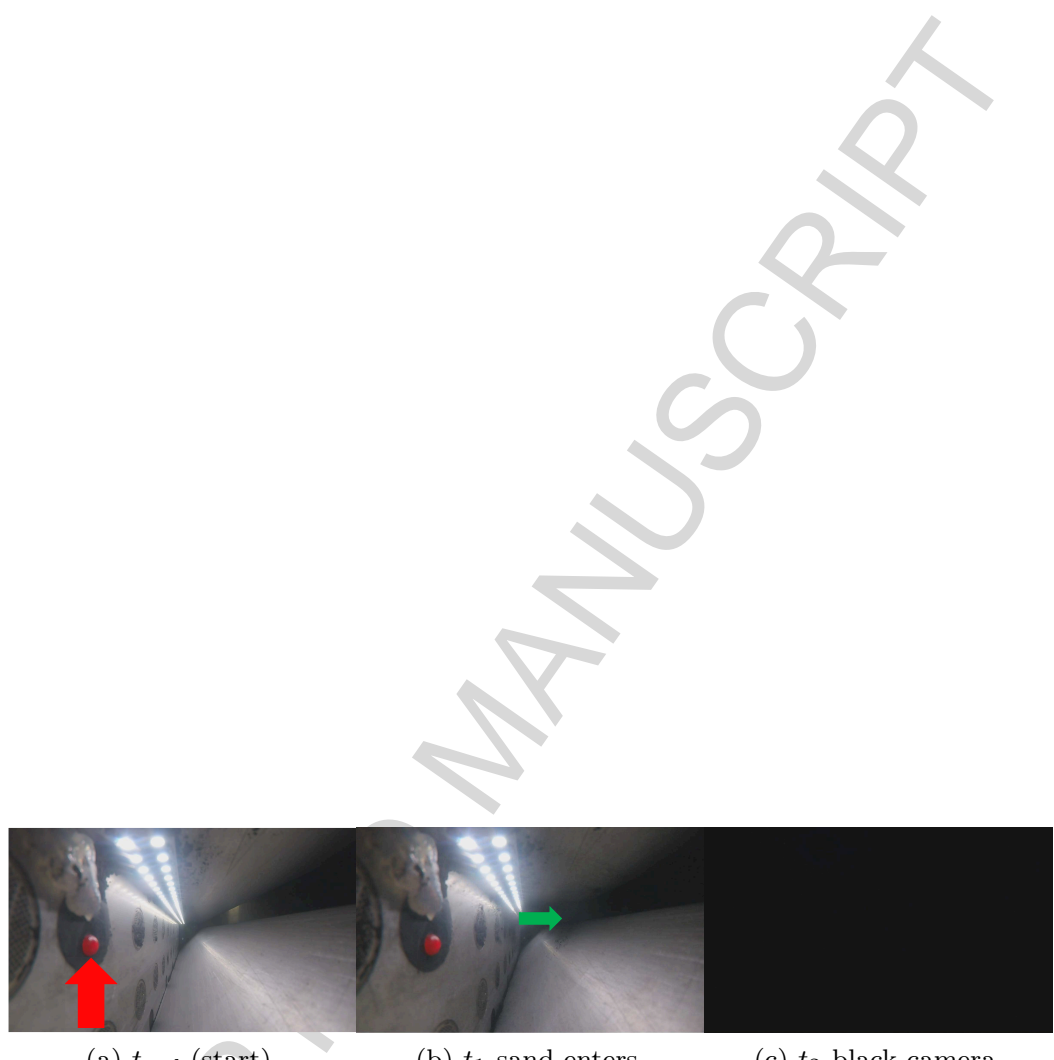

(a) $t_{\text {red }}$ (start).

(b) $t_{1}$ sand enters.

(c) $t_{2}$ black camera

Figure 5: Video footage of the green sand filling of the cavity where a camera is placed in each cavity. (a) The red light indicates when the activation of the sand shot valve occurs. (b) The green sand entering the cavity $t_{1}$. (c) The filling of cavity by the green sand blocking the camera view $t_{2}$ 


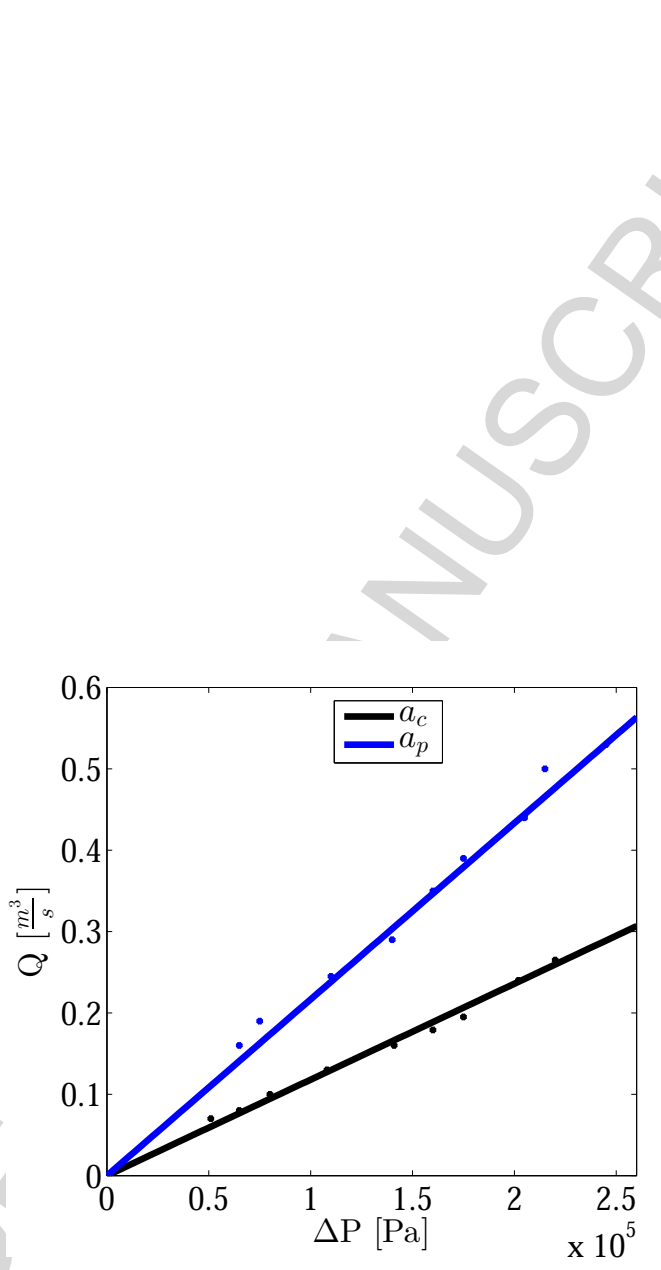

Figure 6: The air flow rate $(Q)$ through the air vent as a function of the pressure drop $(\Delta P)$. The chamber air vent permeability is denoted $a_{c}$ (blue line) and the pattern plate air vents permeability is denoted $a_{p}$ (black line) . 
(a) Chamber top view $\quad 0.094 \mathrm{~m} \quad 0.045 \mathrm{~m}$

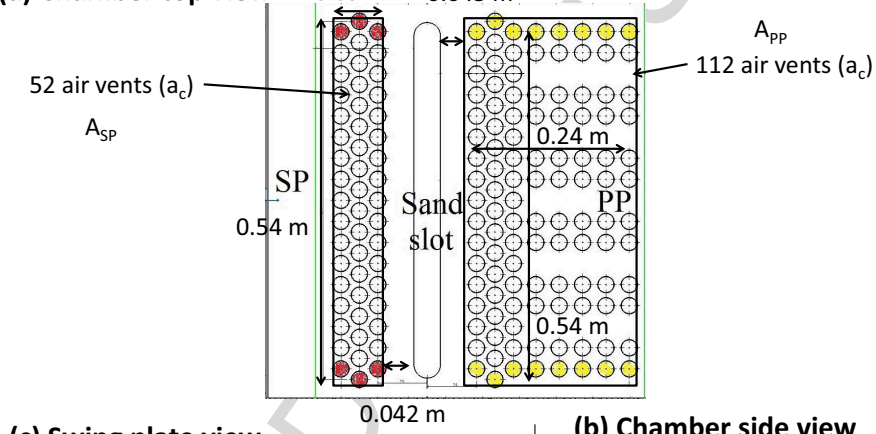

(c) Swing plate view

$042 \mathrm{~m}$

(b) Chamber side view

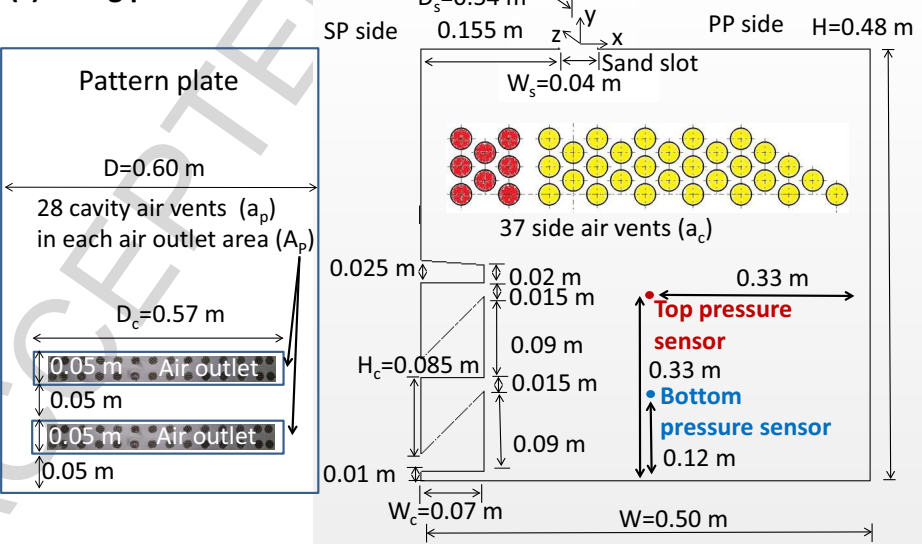

Figure 7: (a) The chamber top view showing the two air outlets - one on the SP side and one on the PP side. (b) The chamber side view with the placements of pressure sensors (top and bottom), side air vents, sand slot, SP side, PP side. (c) The chamber SP view with the pattern plate area for the two air vent areas indicated by name air outlet. 


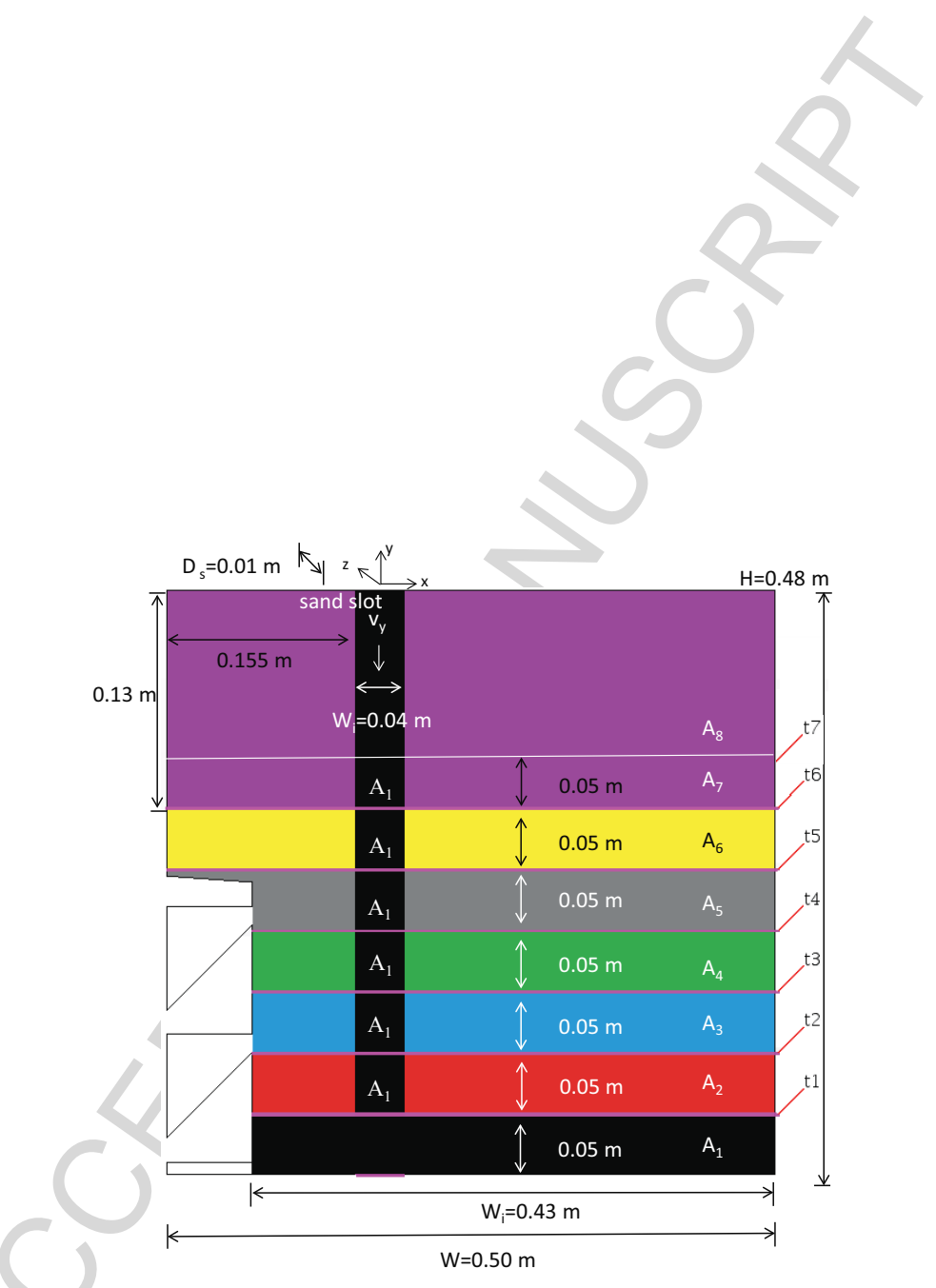

Figure 8: The flow rate found from the chamber measurements and the video footage in the chamber. The chamber is divided into the different areas $\left(A_{1}-A_{7}\right)$ that are filled with green sand at the subsequent times $\left(t_{1}-t_{7}\right)$. 


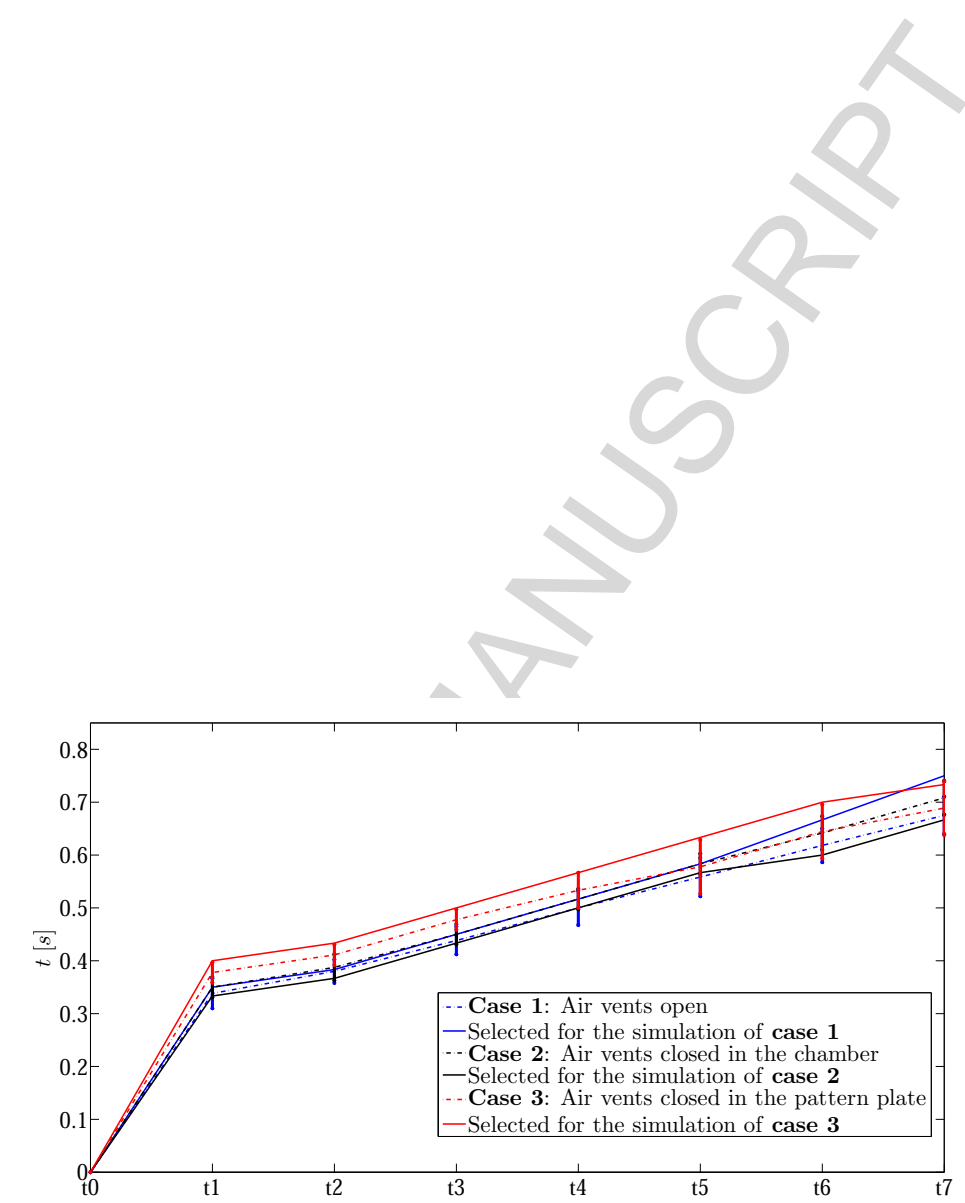

Figure 9: The average experimental filling times of $t_{0}-t_{7}$ for the three cases $1-3$ (dotted lines) and the three selected experimental filling times from cases 1 - 3(full lines). 

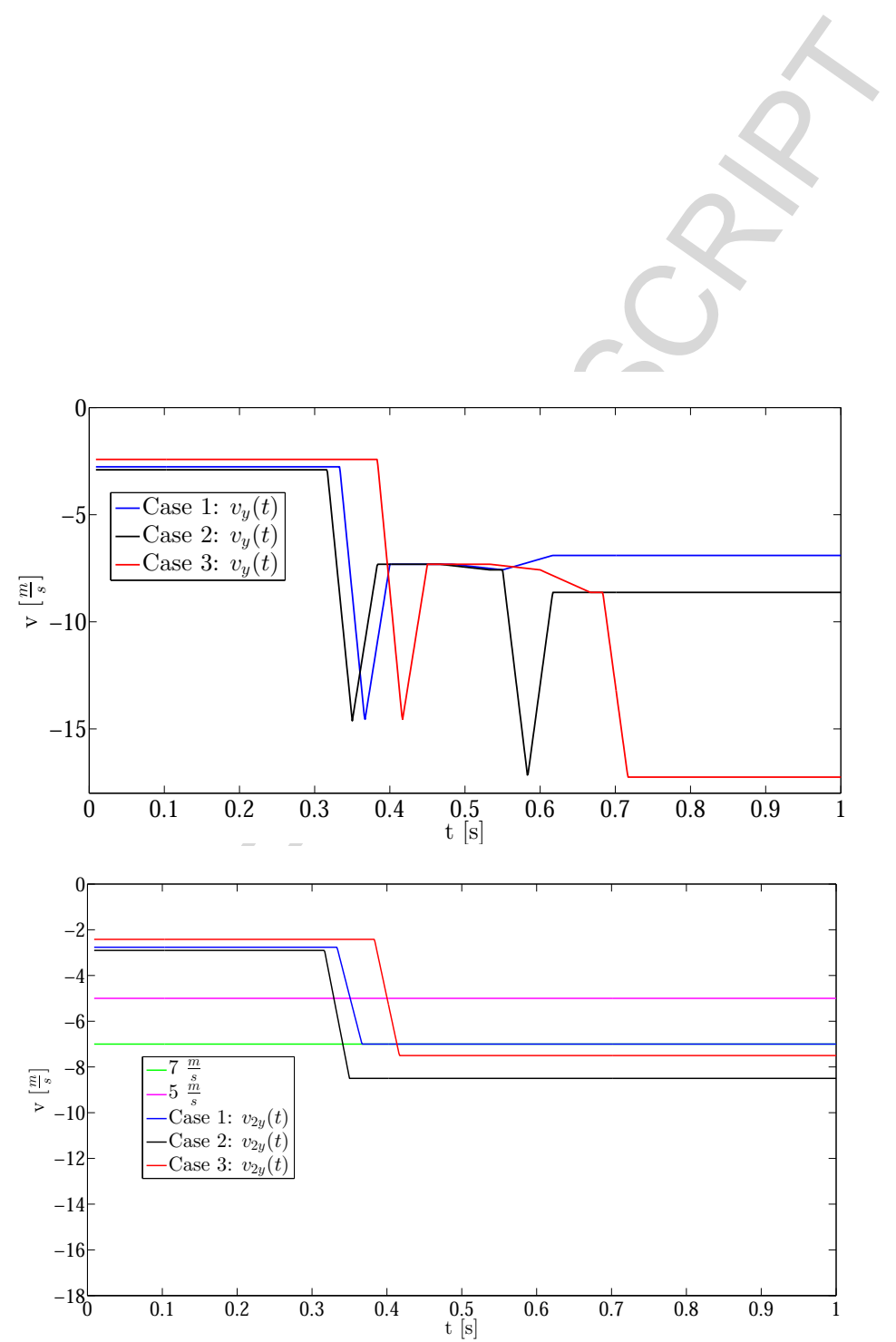

Figure 10: The vertical inlet velocities for the simulations. The time dependent velocities $v_{y}(t)$ for the three cases. The two stage time dependent velocities $v_{2 y}(t)$ and the constant velocities for the three cases 


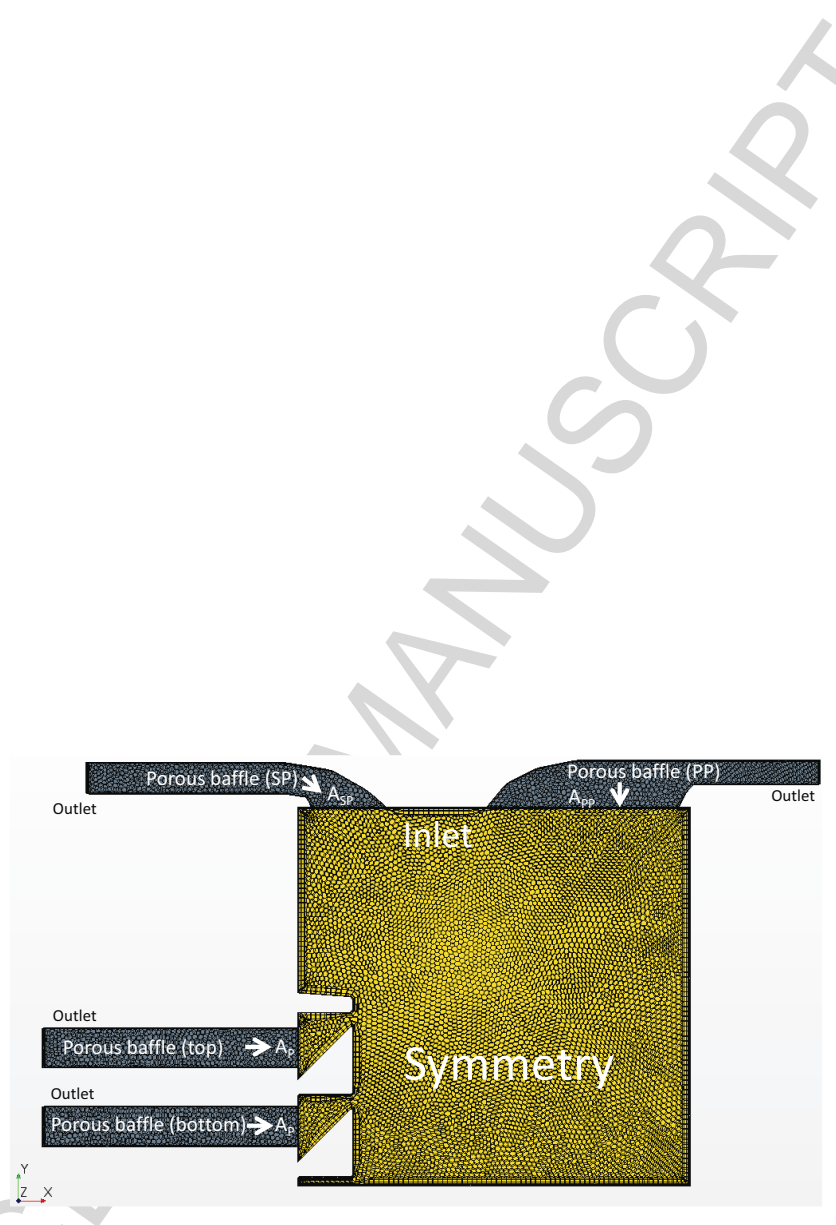

Figure 11: Placements of the boundaries. 

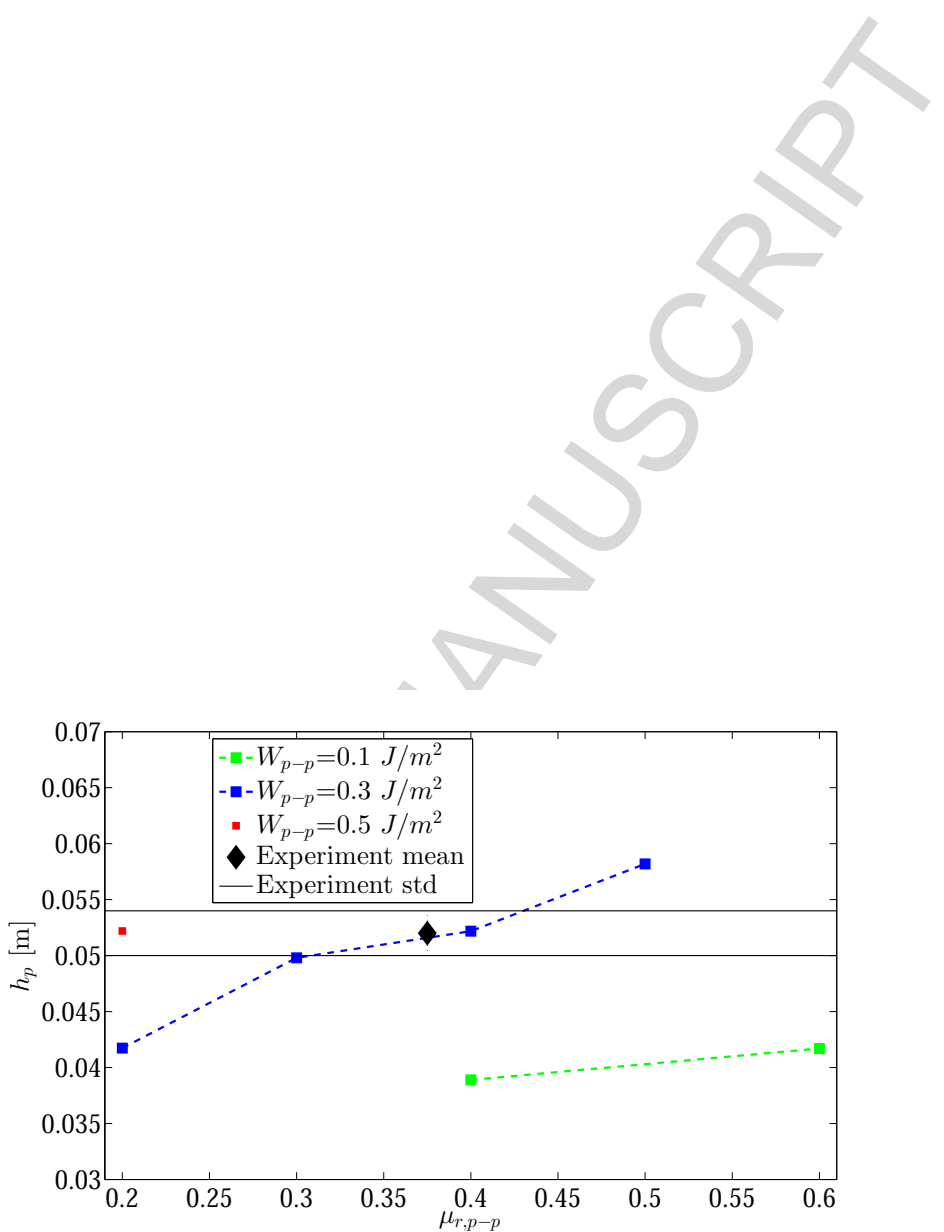

Figure 12: The black diamond is the mean height of the green sand pile experiment of $0.054 m \pm 0.002 \mathrm{~m}$ (black horizontal lines). 


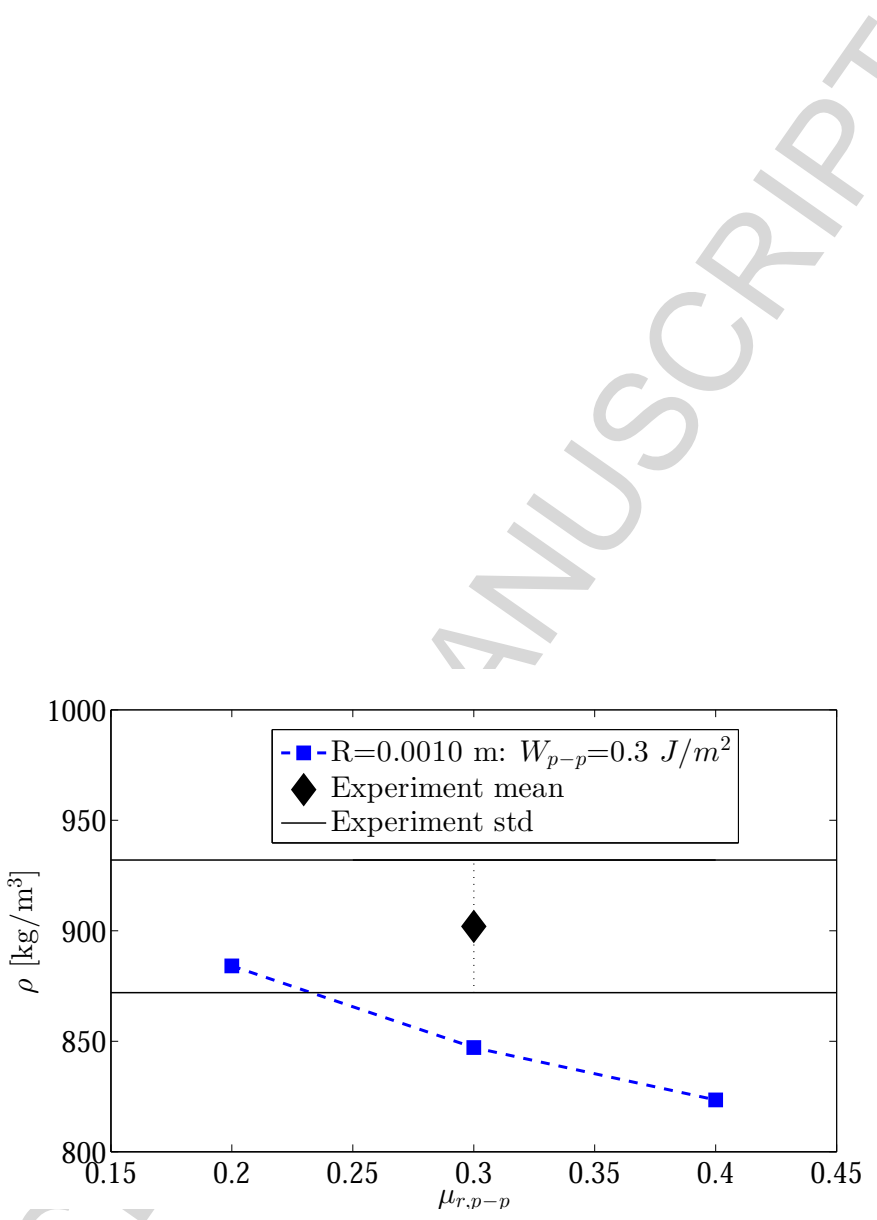

Figure 13: Plot of the density: The black diamond is the mean density of the green sand pile experiment of $902 \pm 30 \frac{\mathrm{kg}}{\mathrm{m}^{3}}$ (thin black line). The DEM simulations were made for the settings for the cohesion value $W_{p-p}=0.3 \frac{\mathrm{J}}{\mathrm{m}^{2}}$ (blue dotted line). 


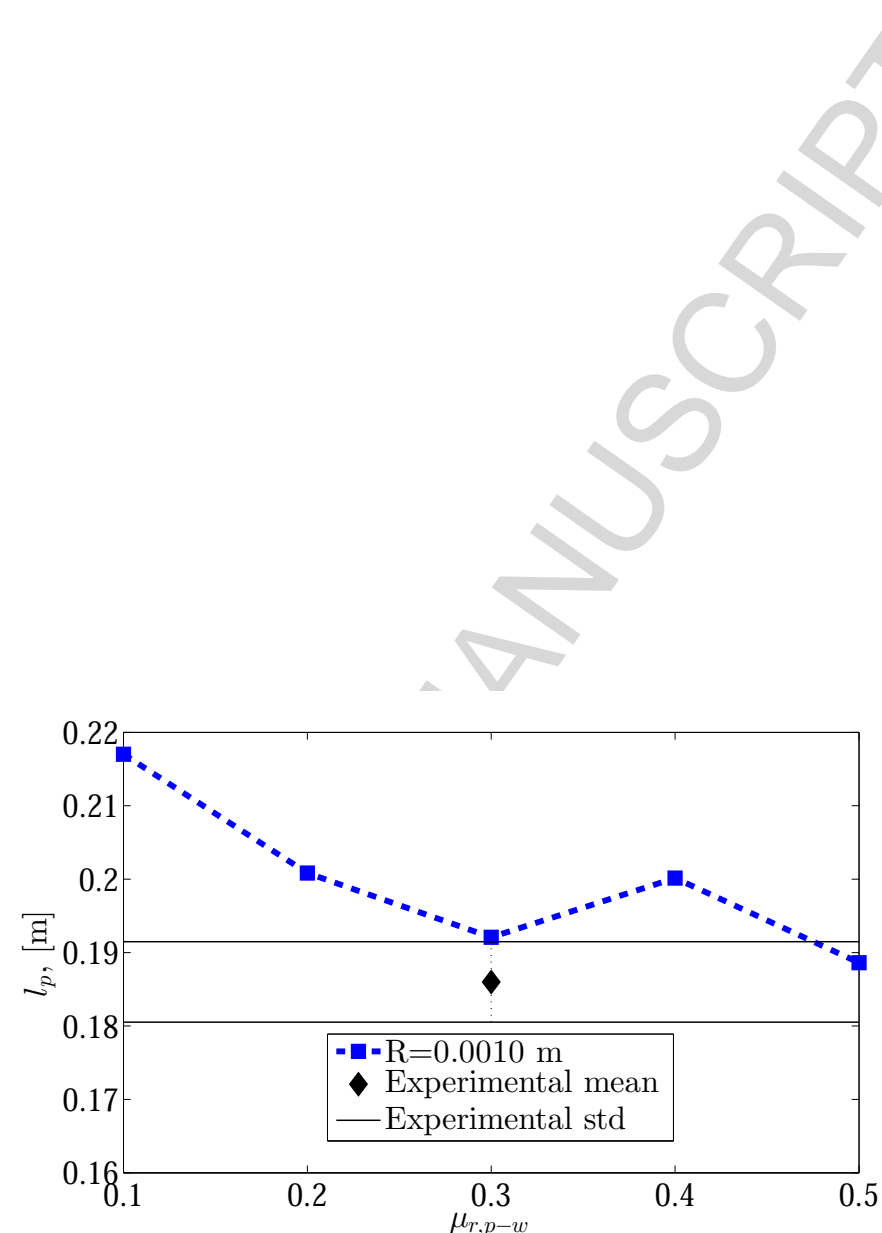

Figure 14: The black diamond is the mean length (diameter) of the green sand slump experiment of $0.186 \pm 0.0548 \mathrm{~m}$ with the standard deviation of $\sigma=5.48 \mathrm{~mm}$ (thin black line). 


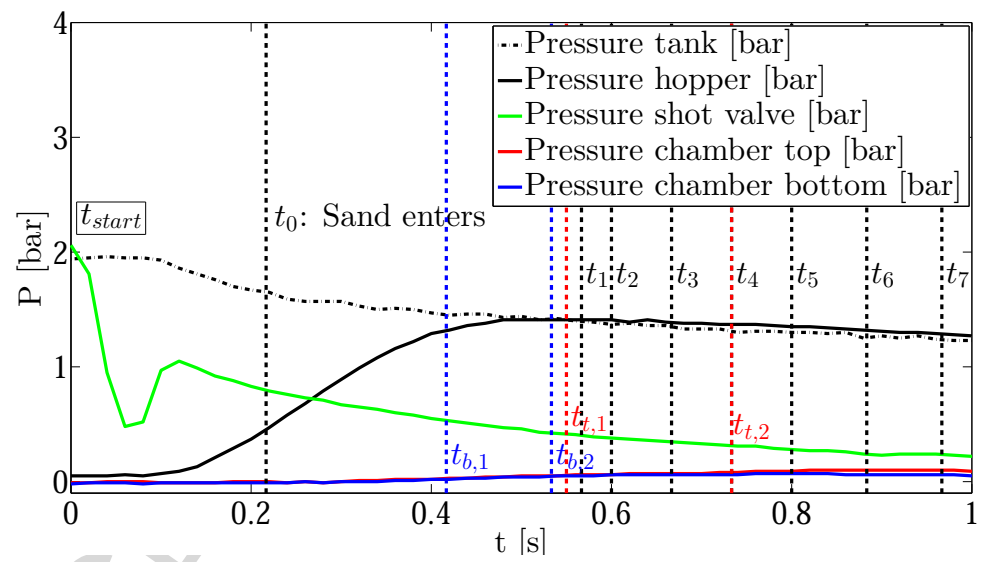

Figure 15: Example from Case 1: The pressure as a function of time is shown in the positions listed from the top to the bottom: The air tank (black dotted line), the shot valve (green), the hopper (black line), the top of the chamber (red line) and the bottom of the chamber (blue line). The atmospheric pressure is used as the reference pressure. The filling times $t_{0}-t_{7}$ in the chamber from the chamber camera $v_{1}$ (black dotted lines). 


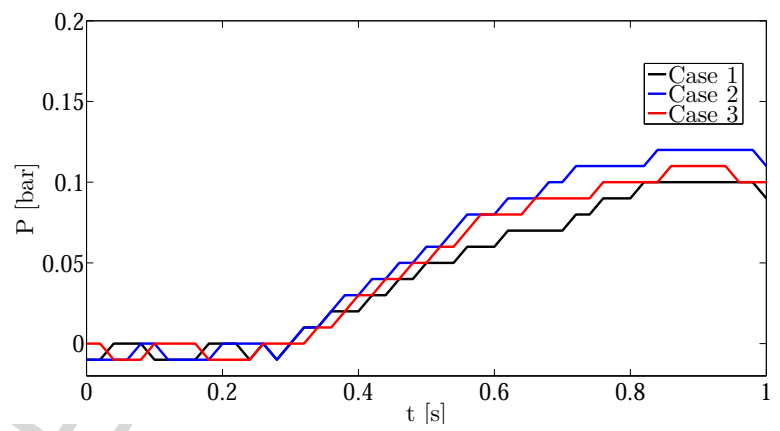

Figure 16: The three cases of experimental pressures measured at the top of the chamber as a function of time with the initial starting time of $t_{0}=0.0 \mathrm{~s}$. The atmospheric pressure is used as the reference pressure. 


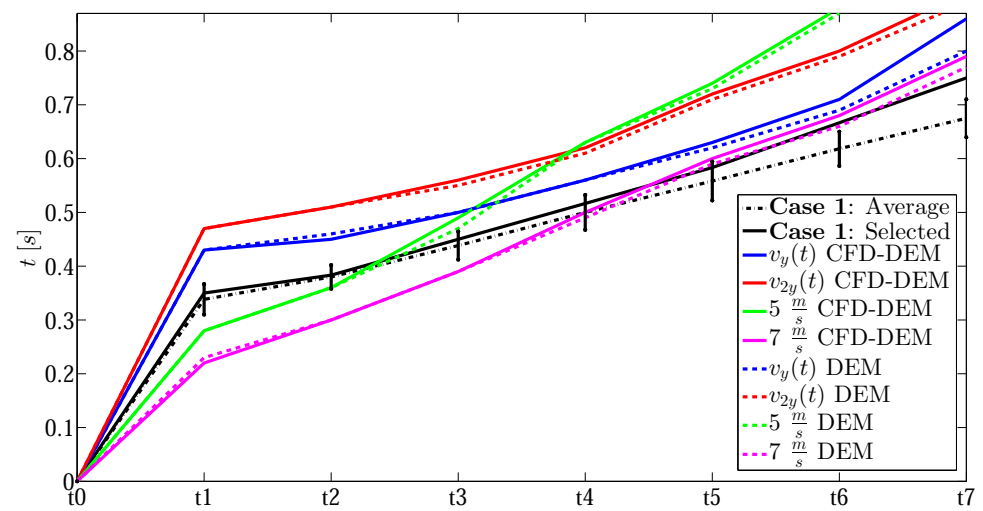

Figure 17: The experimental and simulation filling times of $t_{0}-t_{7}$ for case 1 . 


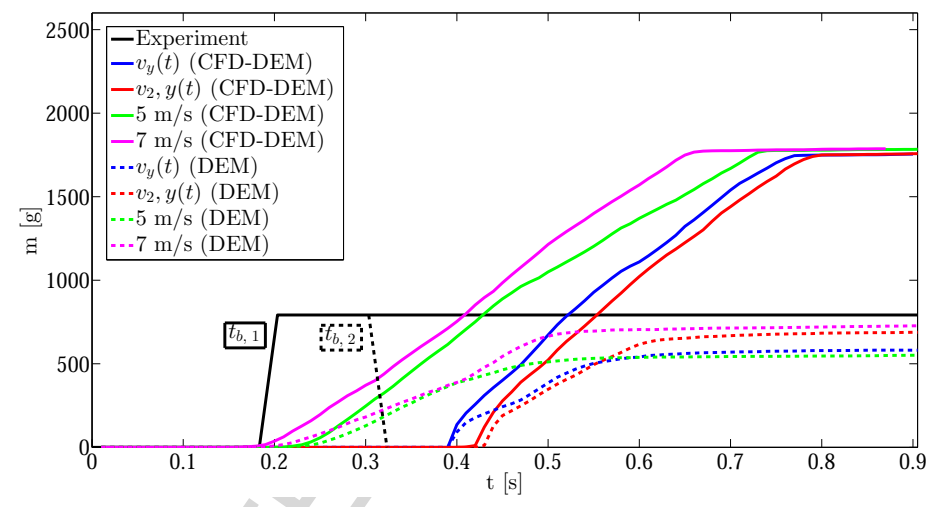

(a)

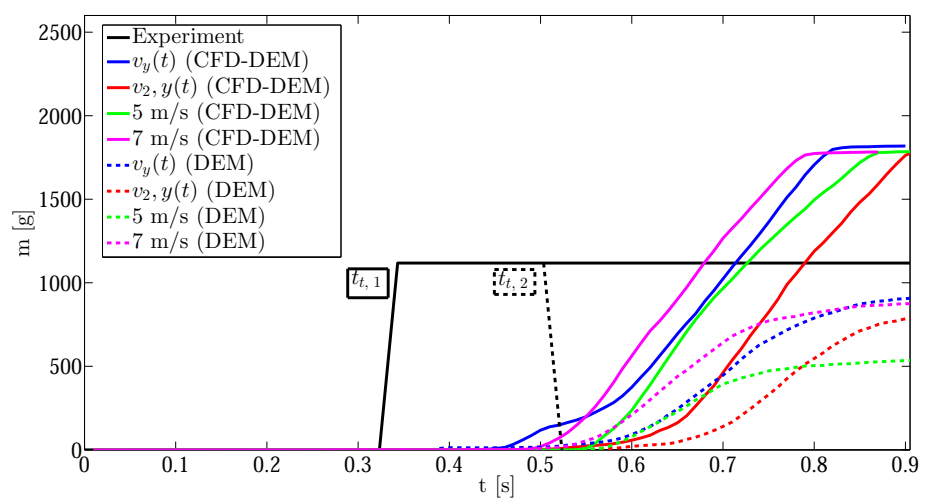

Figure 18: Case 1: The mass as a function of time for the bottom cavity (a) and for the top cavity (b). 


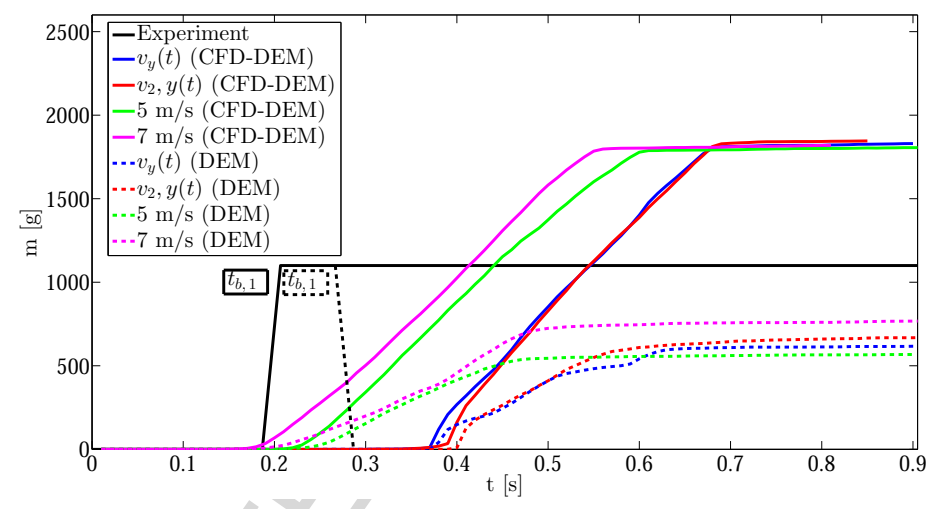

(a)

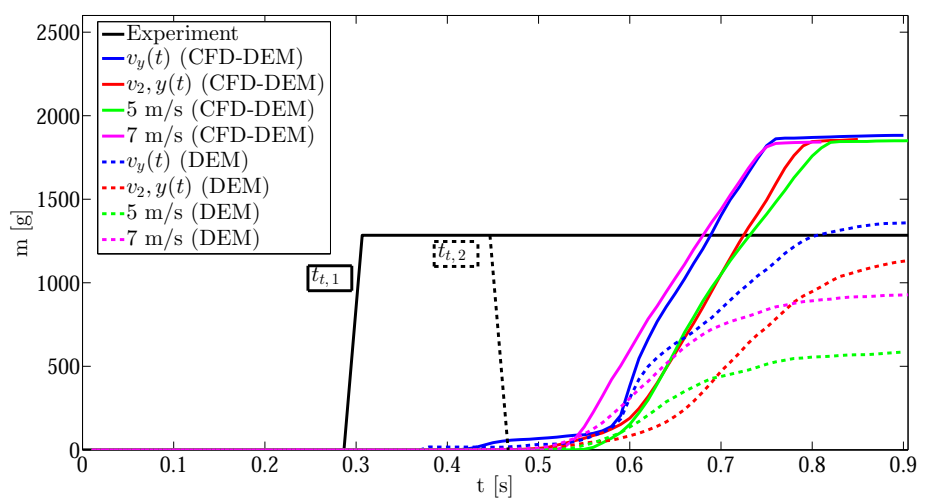

Figure 19: Case 2: The mass as a function of time for the bottom cavity (a) and for the top cavity (b). 


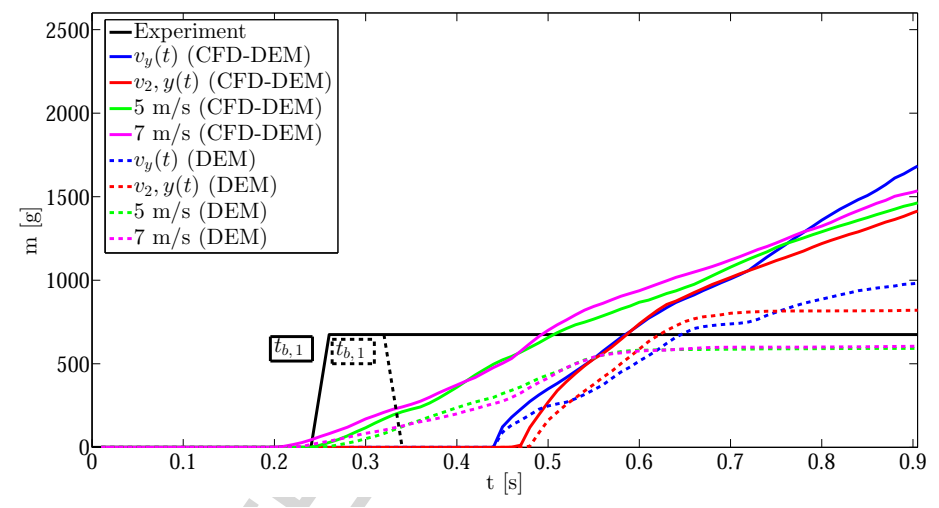

(a)

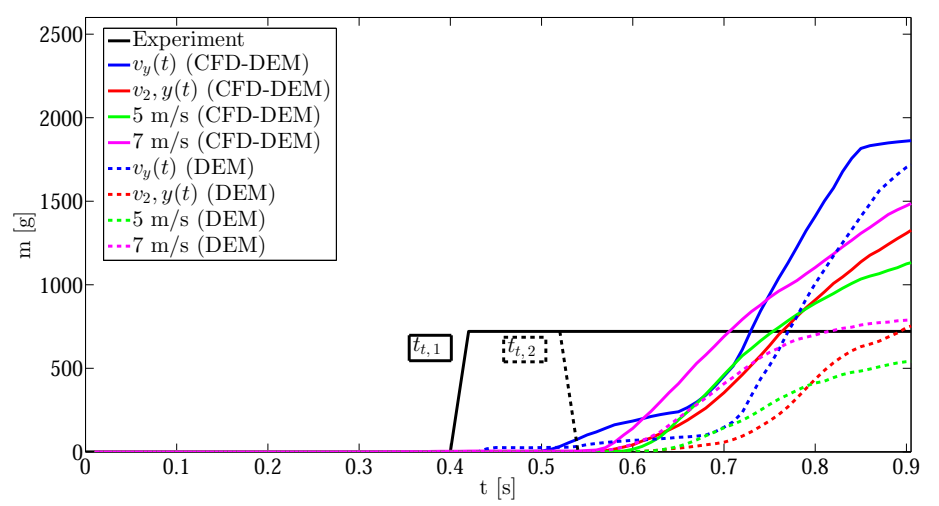

Figure 20: Case 3: The mass as a function of time for the bottom cavity (a) and for the top cavity (b). 


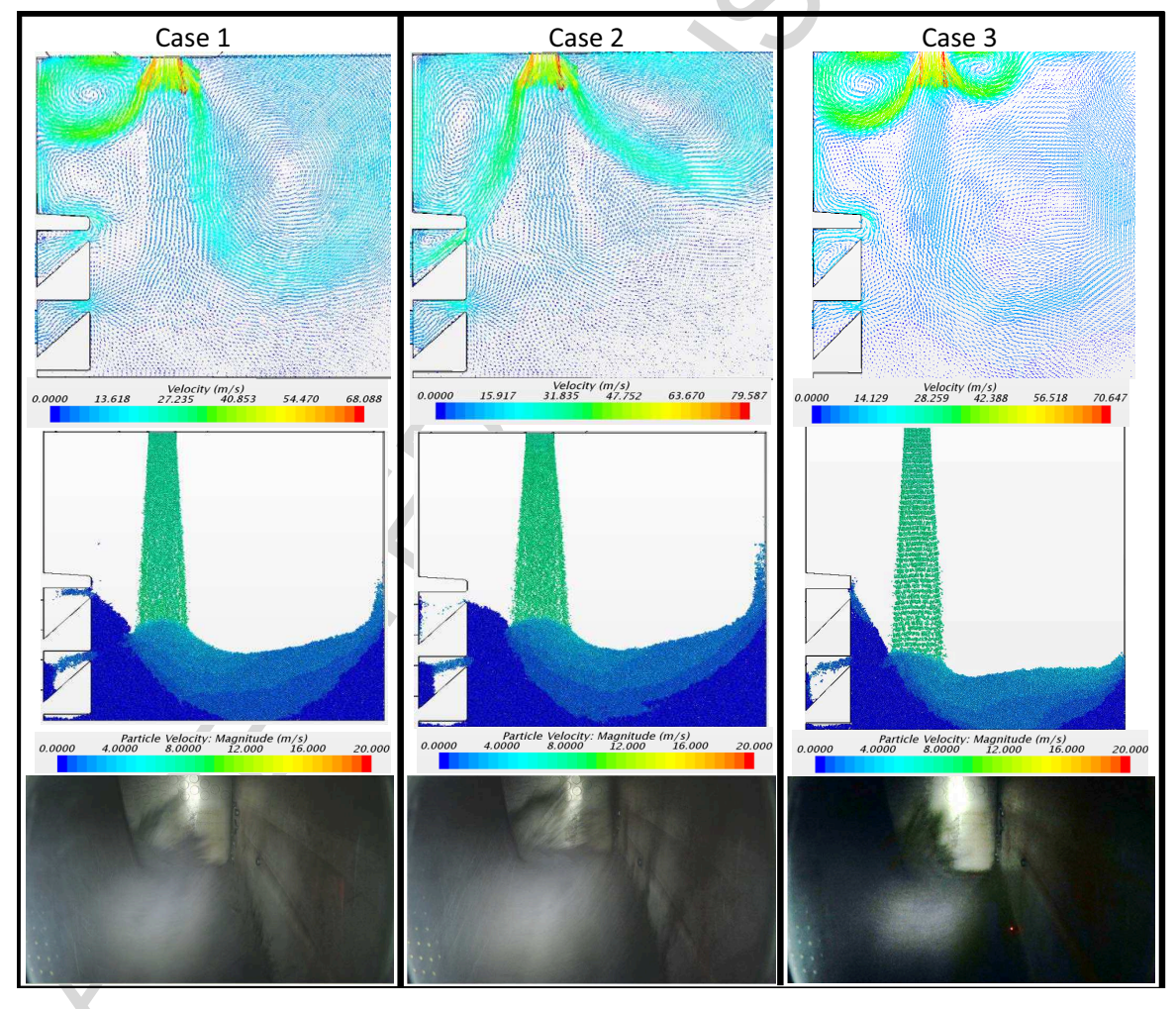

Figure 21: For the selected three cases: The time dependent velocity $v_{y}(t)$ simulation at time $\mathrm{t}=0.50 \mathrm{~s}$. (Top) The velocity of the air phase. (Middle) The velocity of the particles. (Bottom) The experimental video footage at time $\mathrm{t}=0.50 \mathrm{~s}$ 


\section{List of Tables}

1 The experimental air vents settings in the chamber for the three cases. In case 2, 62 air vents of the type $a_{c}$ are blocked in the chamber. Case $3,14 \times 2$ air vents of the type $a_{p}$ are blocked in each cavity on the pattern plate. . . . . . . . . . . 52

2 Simulating of the air vent's settings in the chamber for the three cases. (a) Two sets of air vents are placed on the pattern plate, one in each cavity. . . . . . . . . . . . . . . . . 53

3 Results from the test of the green sand calibrating the model. . . 54

4 General material values for all the simulations. . . . . . . . . . 55

5 The calibrated DEM model for simulating the DISAMATIC process. . . . . . . . . . . . . . . . 56

6 (left) Masses in the two cavities from the three cases together with the selected experiments. (right) The compactability test results from the three cases. . . . . . . . . . . . 57 
Table 1: The experimental air vents settings in the chamber for the three cases. In case 2,62 air vents of the type $a_{c}$ are blocked in the chamber. Case $3,14 \times 2$ air vents of the type $a_{p}$ are blocked in each cavity on the pattern plate.

\begin{tabular}{|c|c|c|c|}
\hline Case & 1 & 2 & 3 \\
\hline SP top air vents opened $\left(a_{c}\right)$ & 52 & 0 & 52 \\
PP air vents, opened $\left(a_{c}\right)$ & 112 & 112 & 112 \\
Pattern plate air vents opened $\left(a_{p}\right)$ & $2 \times 28$ & $2 \times 28$ & $2 \times 14$ \\
Side air vents opened, $(\mathrm{n})$ & $2 \times 37$ & $2 \times 32$ & $2 \times 37$ \\
Total opened air vents $\left(a_{c}+a_{p}\right)$ & 294 & 232 & 266 \\
Experimental repetitions & 7 & 3 & 3 \\
\hline
\end{tabular}


Table 2: Simulating of the air vent's settings in the chamber for the three cases. (a) Two sets of air vents are placed on the pattern plate, one in each cavity.

\begin{tabular}{llll} 
Case & 1 & 2 & 3 \\
\hline SP air vents, $(n)$ & 52 & 0 & 52 \\
$A_{S P},\left[\mathrm{~m}^{2}\right]$ & $507.6 \times 10^{-4}$ & No & $507.6 \times 10^{-4}$ \\
$\beta_{S P},\left[\frac{\mathrm{m}}{\mathrm{s}}\right]$ & 766.2 & No & 766.2 \\
\hline $\mathrm{PP}$ air vents, $(n)$ & 112 & 112 & 112 \\
$A_{P P},\left[\mathrm{~m}^{2}\right]$ & $1296 \times 10^{-4}$ & $1296 \times 10^{-4}$ & $1296 \times 10^{-4}$ \\
$\beta_{P P},\left[\frac{\mathrm{m}}{\mathrm{s}}\right]$ & 908.3 & 908.3 & 908.3 \\
\hline Pattern plate $^{a},(n)$ & 28 & 28 & 14 \\
$A_{p},\left[\mathrm{~m}^{2}\right]$ & $285.0 \times 10^{-4}$ & $285.0 \times 10^{-4}$ & $142.5 \times 10^{-4}$ \\
$\beta_{p},\left[\frac{\mathrm{m}}{\mathrm{s}}\right]$ & 435.0 & 435.0 & 435.0 \\
\hline
\end{tabular}


Table 3: Results from the test of the green sand calibrating the model.

\begin{tabular}{llll} 
Material property & average & std & Rep. \\
\hline Static friction coefficient $\mu_{s, p-p}$ & 0.57 & \pm 0.04 & 90 \\
Static friction coefficient $\mu_{s, p-p}$ & 0.33 & \pm 0.02 & 26 \\
Sand pile height $h_{p}$ & $52 \times 10^{-3} \mathrm{~m}$ & $2 \times 10^{-3} \mathrm{~m}$ & 15 \\
Density $\rho_{\text {Bulk }}$ & $902 \frac{\mathrm{kg}}{\mathrm{m}^{3}}$ & $\pm 30.0 \frac{\mathrm{kg}}{\mathrm{m}^{3}}$ & 27 \\
Slump length $l_{p}$ & $186 \times 10^{-3} \mathrm{~m}$ & $5.48 \times 10^{-3} \mathrm{~m}$ & 25 \\
Compactability & $36 \%$ & $\pm 2.1 \%$ & 27 \\
Water content $\%$ & $3.5 \%$ & $\pm 0.2 \%$ & 42 \\
\hline
\end{tabular}


Table 4: General material values for all the simulations.

Material property Value

DEM particle radius, $(\mathrm{R})$ $0.001 \mathrm{~m}$

Solid density of the chamber wall $\left(\rho_{\text {wall }}\right)$ $7500 \mathrm{~kg} / \mathrm{m}^{3}$

Youngs modulus of the green sand, $\left(E_{p}\right)$ $17000 \mathrm{MPa}$

Youngs modulus of the chamber wall, $\left(E_{w}\right)$ $200000 \mathrm{MPa}$

Poisson ratio of the green sand, $(\nu)$ 0.3

Poisson ratio of the chamber wall, $(\nu)$

0.3

Coefficient of restitution particle-particle, $\left(e_{n}\right) \quad 0.01$

Coefficient of restitution particle-wall, $\left(e_{t}\right)$

0.01

Gravity (g)

$9.82 \frac{\mathrm{m}}{\mathrm{s}^{2}}$

Particle-wall static friction, $\left(\mu_{s, p-w}\right)$

Particle-particle static friction, $\left(\mu_{s, p-p}\right)$

0.57

The simulation time step, $(\Delta t)$

$10^{-5} \mathrm{~s}$ 


\begin{tabular}{ll} 
Table 5: The calibrated DEM model for simulating the DISAMATIC process. & Value \\
Material property & 0.4 \\
\hline Particle-particle rolling friction coefficient $\left(\mu_{r, p-p}\right)$ & $0.3 \frac{\mathrm{J}}{\mathrm{m}^{2}}$ \\
Particle-particle cohesion work $\left(W_{p-p}\right)$ & $1900 \frac{\mathrm{kg}}{\mathrm{m}^{3}}$ \\
Particle density $\rho_{D E M}{ }^{*}$ & 0.5 \\
Particle-wall rolling friction coefficient $\left(\mu_{r, p-w}\right)$ & $10^{-4} \mathrm{~s}$ \\
The simulation time step, $(\Delta t)$ &
\end{tabular}


Table 6: (left) Masses in the two cavities from the three cases together with the selected experiments. (right) The compactability test results from the three cases.

\begin{tabular}{|llll|ll|}
\hline Case & Rep. & Bottom cavity $[\mathrm{g}]$ & Top cavity $[\mathrm{g}]$ & Rep. & $\rho_{\text {sand }}\left[\mathrm{kg} / \mathrm{m}^{3}\right]$ \\
\hline 1 & 7 & $593 \pm 189$ & $961 \pm 237$ & 18 & $920 \pm 50.1$ \\
1 & Selected for simulation & 792 & 1118 & & \\
\hline 2 & 3 & $933 \pm 215$ & $1220 \pm 72.5$ & 9 & $970 \pm 19.7$ \\
2 & Selected for simulation & 1100 & 1284 & & \\
\hline 3 & 3 & $623 \pm 47.7$ & $687 \pm 30.2$ & 9 & $937 \pm 28.6$ \\
3 & Selected for simulation & 674.8 & 721 & & \\
\hline
\end{tabular}




\section{Graphical abstract}

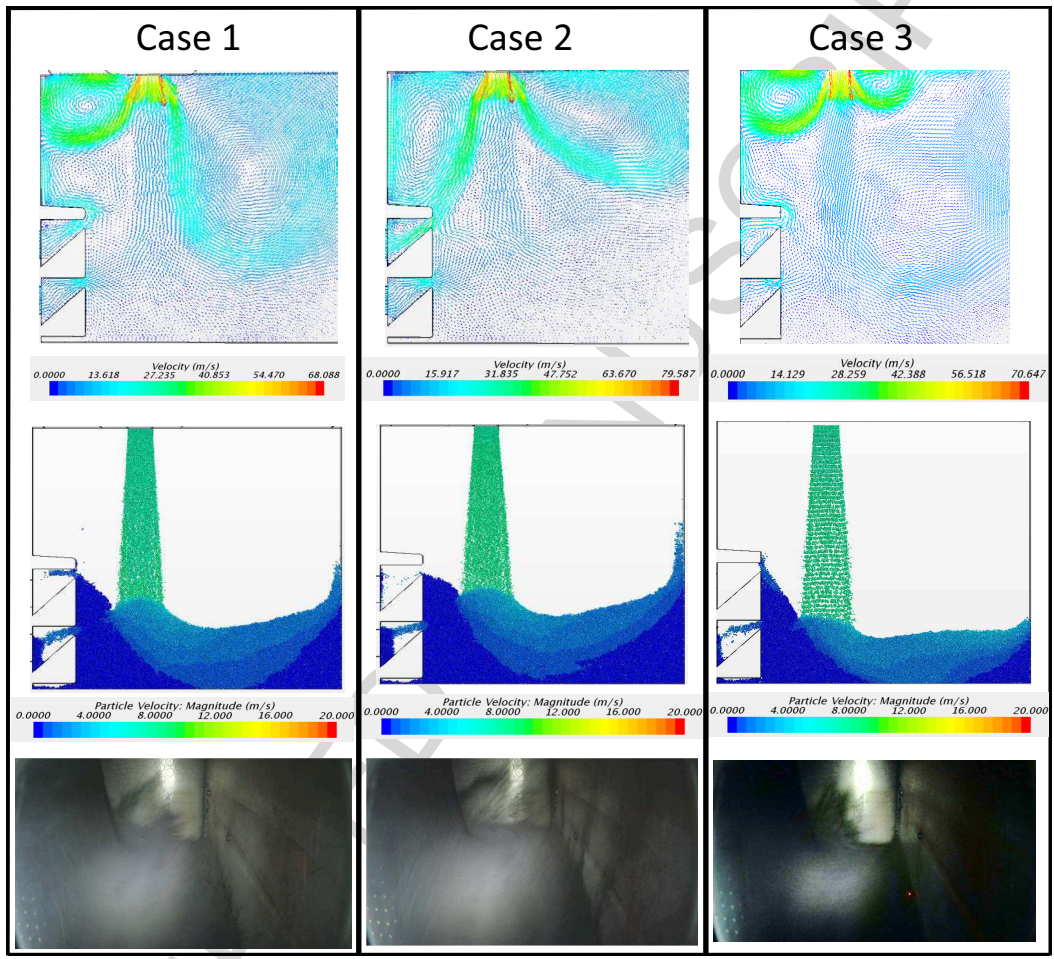

- The DISAMATIC process and the geometry with the two specially designed cavities for the simulation and the experiment.

- Case 1 , case 2 and case 3 for the simulated air flow (top row), the simulated granular flow (middle row) and the experimental flow profile (bottom row). 


\section{Highlights}

- The calibration of the DEM model was performed with several experiments.

- A special cavity geometry was designed for investigating the locally deposition of green sand during the DISAMATIC process.

- Comparing the dynamics of the granular flow process to DEM and CFDDEM simulations. 